\title{
UN MONUMENTO PARA LA ETERNIDAD. EL SEPULCRO DE LOS CONDES DE NIEVA EN VALVERDE DE LA VERA (CÁCERES) Y EL ESCULTOR FLAMENCO EGAS CUEMAN*
}

\author{
A MONUMENT FOR ETERNITY. THE TOMB OF THE COUNTS OF \\ NIEVA IN VALVERDE DE LA VERA (CÁCERES) AND THE FLEMISH \\ SCULPTOR EGAS CUEMAN
}

\author{
FLORENCIO-JAVIER GARCÍA MOGOLLÓN \\ Universidad de Extremadura
}

Recibido: 20/10/2018

Aceptado: 23/01/2019

\section{RESUMEN}

Se analiza desde el punto de vista histórico-artístico un interesante monumento funerario de la década de 1480, obra que atribuimos al taller del notable escultor flamenco Egas Cueman, uno de los mejores en tiempo de los Reyes Católicos. Es un sepulcro de inspiración hispano-flamenca y, pese a los deterioros, de gran calidad, pues destaca entre los conservados en Extremadura.

Palabras clave: Nieva, Zúñiga, escultura gótica, hispano-flamenco, Cueman, Monasterio de Guadalupe.

\section{ABSTRACT}

An interesting funerary monument from the decade of 1480 is analyzed from the historical-artistic point of view, a work that we attribute to the workshop of the

\footnotetext{
* El presente trabajo amplía desde el punto de vista histórico-artístico y documental la ponencia que presentamos al "I Encontro/Encuentro Nova-Complutense sobre (a) Iberia Medieval. Desenhar a Eternidade, Diseñar la Eternidad. Cenografias funerárias na Ibéria Medieval, Escenografías funerarias en la Iberia Medieval", celebrado en Lisboa, Instituto Cervantes de Lisboa y Mosteiro da Batalha, entre los días 1-4 de marzo de 2018.
} 
remarkable flemish sculptor Egas Cueman, one of the bests in the days of the Catholic Monarchs. It is a sepulcher of hispanic-flemish inspiration and, despite the deteriorations, of great quality, as it stands out among those preserved in Extremadura.

Keywords: Nieva, Zúñiga, gothic sculpture, hispanic-flemish, Cueman, Guadalupe Monastery.

La señorial villa de Valverde, uno de los conjuntos de arquitectura popular mejor conservados del norte de Extremadura ${ }^{1}$, domina un precioso paraje de la cacereña comarca de la Vera y fue cabeza de un extenso señorío junto a las localidades vecinas de Viandar (independizada en 1645), Talaveruela, Villanueva (se independizó en 1643) y Madrigal, que se incluían en su jurisdicción y que, en conjunto, tenían 600 vecinos en 1494.

La villa de Valverde nació por la necesidad de repoblar dichos territorios tras la fundación de Plasencia y su obispado, al que pertenece, por Alfonso VIII en 1189. Inicialmente sería una aldea sin parroquia, pues en el año 1254 aún no la tenía y quizá hacía sus funciones una modesta ermita o pequeña capilla. Lo cierto es que en la fecha citada no se menciona tal parroquia en los estatutos de la Catedral de Plasencia para el dezmatorio. En cambio sí se nombran otras parroquias de la comarca, como las de Jaraíz, Cuacos o Losar, la última muy cercana a Valverde ${ }^{2}$.

A finales del siglo XIII Valverde tenía un censo de cierta entidad, porque en ese tiempo el rey Sancho IV el Bravo (1284-1295) donó el pueblo, en calidad de señorío, al ilustre placentino don Nuño Pérez de Monroy, notario mayor de Castilla, abad de Santander, arcediano de Campóo y canciller de la reina doña María de Molina; la donación se hizo efectiva el 30 de junio de 1301, cuando el concejo de Plasencia confirmó esa posesión:

"Nos el conçejo de Plazençia por fazer bien e onrrada ayuda a vos Nuño Pérez, arcediano de Campóo, abbad de Santander e chanciller mayor de la reyna doña María nuestra señora, damos vos la nuestra aldea de la Vera que dizen Valverde... por juro de heredad para sienpre jamás... fecha treynta días de junio era de mill e trezientos e treynta e nueve años...”’.

1 Tiene la categoría de Conjunto Histórico-Artístico por Decreto del 31 de diciembre de 1970 (BOE de 2 de febrero de 1971).

2 Elisa Carolina de Santos Canalejo, El siglo XV en Plasencia y su tierra (Cáceres: 1981), 3.Toma el dato de Vicente Paredes Guillén, Los Zúñiga, Señores de Plasencia (Cáceres: 1909), 65.

3 Archivo Histórico de la Nobleza, FRÍAS, C. 445, D.1. 
El 15 de febrero de 1303, en Cuéllar, Fernando IV el Emplazado renovó a Nuño Pérez de Monroy la concesión de los lugares de Jarandilla y Valverde ${ }^{4}$. El mismo Fernando IV confirmó de nuevo la posesión en $1309^{5}$, revalidada a Nuño Pérez de Monroy por Alfonso XI en Burgos el 28 de julio de $1315^{6}$ y en Valladolid el 17 de diciembre de $1325^{7}$. En 1326 heredó el señorío y mayorazgo de Monroy, Valverde y Talaván, confirmado por Alfonso XI y luego por Juan I, su hermano Fernán Pérez de Monroy el Viejo, segundo señor de Valverde y constructor del magnífico castillo de Monroy (Cáceres) ${ }^{8}$. Posteriormente lo recibió el primogénito homónimo de este último, que retuvo el mencionado estado feudal por privilegio de Alfonso XI de 30 de diciembre de 1344. Después de algunas vicisitudes (Enrique II confirmó el 12 de febrero de 1371 la merced que Fernán Pérez había hecho por su testamento a su hija Estefanía Fernández ${ }^{9}$ ) pasó el señorío a manos de su hija Catalina Alonso de Monroy y del esposo de ésta, Mosén Guirao, y luego a las del hijo de ambos, Fernán Pérez de Monroy III, quinto señor de Valverde (por ratificación de Juan I en 1379), el cual luchó encarnizadamente con los Almaraces, enemigos irreconciliables de su familia: Juan Gómez de Almaraz llegó a poner sitio al castillo de Valverde a fines del siglo XIV, fracasando y muriendo en el empeño. Fernán Pérez de Monroy III falleció con más de setenta años asesinado por Diego Gómez de Almaraz, que había jurado vengar la muerte de su padre. Cuyo castillo, hoy ruinoso en parte como consecuencia del abandono y de los derrumbes de 1895, se alzó desde comienzos del siglo XIV y sufrió modificaciones a fines del siglo XV, sobre todo en la torre del homenaje, integrándose algunas de sus estructuras en la iglesia parroquial, como veremos.

Posteriormente heredó el señorío, por derecho de consorte, el mariscal de Castilla y señor de Arroyo (hoy de la Luz) Garci González de Herrera, que casó con Estefanía Fernández, hija del quinto señor de Valverde. Al respecto hay una cierta confusión documental, porque el 9 de agosto de 1400 Garci González donó Valverde a Alfonso de Monroy ${ }^{10}$, el 8 de enero de 1404 entregó Valverde, Talaván y otras aldeas al infante don Fernando, señor de Lara ${ }^{11}$, y del 30 de mayo del mismo año 1404 data una real cédula amparando a Estefanía

4 Archivo Histórico de la Nobleza, FRÍAS, C. 1362, D.1.

5 Archivo Histórico de la Nobleza, FRIAS. C.1324.D. 11, 1 de enero de 1309-31 de diciembre de 1309.

6 Archivo Histórico de la Nobleza, FRÍAS, C.1362, D.2.

7 Archivo Histórico de la Nobleza, FRÍAS, C.445, D.1.

8 Archivo Histórico de la Nobleza, FRÍAS, C. 1324, D. 11.

9 Archivo Histórico de la Nobleza, FRÍAS, C.445,D.2.

10 Archivo Histórico de la Nobleza, FRÍAS, C. 445, D.6.

11 Archivo Histórico de a Nobleza, FRÍAS,C.445, D.7. 
Fernández en la posesión de Valverde ${ }^{12}$. El problema derivaba del hecho de que Garci González de Herrera y Estefanía no tuvieron descendencia y esta fue la razón por la que finalmente el señorío se cedió a doña Beatriz de Portugal, séptima señora de Valverde. Doña Beatriz casó con don Pedro Niño y tuvieron una hija, Leonor Niño de Portugal, octava señora de Valverde ${ }^{13}$, que desposó con don Diego López de Zúñiga en 1442, quienes se enterraron en el sepulcro que comentaremos. Su unión explica que, desde ese momento, el señorío de Valverde pasase a depender de la poderosa familia Zúñiga —emparentada luego con los Velasco-, que lo conservó hasta el siglo XIX. Prueba del dominio de los Zúñiga sobre la aldea de Valverde es el magnífico rollo o picota que se conserva, obra de finales del siglo XV o inicios del XVI que contiene los escudos de los Zúñiga y de los Velasco, condes de Nieva, y también las cadenas simbólicas de los primeros ${ }^{14}$.

En el año 1455 se produjeron diversos escándalos como consecuencia de la posesión de los lugares de Valverde y Talaván, que se disputaban Gómez (García) de Herrera (copero mayor del rey) y el citado Diego López de Estúñiga (sic); por ello, temporalmente se hizo entrega de dichos lugares a Gómez de Benavides, para que los administrase en nombre del rey hasta que se comprobase su pertenencia ${ }^{15}$. Finalmente, el 22 de julio de 1455 tomó posesión de la villa de Valverde, "por carta del rey don Juan", el mencionado Diego López de Zúñiga ${ }^{16}$.

12 Archivo Histórico de la Nobleza, FRÍAS, C.1406, D.5.

13 El señorío lo adquirió el 15 de abril de 1452 Leonor (la menor de las tres hijas que tuvieron Beatriz y Pedro) por compra a su hermana Inés Niño, abadesa del monasterio de Santa Clara de Valladolid, a cambio de 23.000 maravedíes de juro: véase Archivo Histórico de la Nobleza, FRÍAS, C.273. D.7-8.

14 Véanse estos datos en Florencio-Javier García Mogollón, Viaje artístico por los pueblos de la Vera (Cáceres). Catálogo Monumental (Madrid: Pedro Cid, 1988), 280-281 y 285-288; consúltese también Gervasio Velo Nieto, Castillos de Extremadura (Madrid: 1968), 631-649. Más noticias sobre el señorío de Valverde se localizan en José Manuel Novoa Pérez, Vasallos, señores y concejos en la Vera de Plasencia. Historia del señorio de Valverde de la Vera (siglos XIII-XVIII) (Mérida: Academia Europea de Yuste, 2009); Idem, Historia del señorio de Valverde de la Vera (Bubok Publishing S.L., 2015): es una segunda edición electrónica y en papel bajo demanda del anterior. Otros trabajos sobre Valverde son los de José Bueno Rocha, Notas históricas de Valverde de la Vera (Ayuntamiento de Valverde de la Vera: 1995), Ángel Correa Pérez, Historia del señorio de Valverde de la Vera (Asociación Cultural de Amigos de la Vera-Consejería de Cultura y Patrimonio de la Junta de Extremadura: 1998) y Susana Mayero Higuero, Estudio histórico-artístico de Valverde de la Vera (2007). Un blog de internet en el que se recogen algunos datos interesantes es el de Manuel Vicente Fernández Sánchez: manuelvicentefs.files.wordpress.com/ 2014/03/una-cronologc3ada-sob.

15 Real Provisión de Enrique IV del 15 de marzo de 1455, Archivo Histórico de la Nobleza, FRÍAS, C. 10 , D.1.

16 Archivo Histórico de la Nobleza, ALTAMIRA, C. 3, D. 227. Incluimos la carta en el apéndice documental. 
Posteriormente Enrique IV concedió el condado de Nieva ${ }^{17}$ al citado Diego López de Zúñiga. La fecha visible en el sepulcro que analizaremos, 9 de enero de 1469, quizá implica que en ese tiempo el condado de Nieva ya era efectivo, siéndolo, desde luego, en agosto de 1470 pues ya se denomina a don Diego en la documentación con ese título: así se lo menciona en una Real Provisión de Enrique IV, suscrita ante el escribano de cámara Juan López Curiel ${ }^{18}$, concediendo a Diego López de Zúñiga (primer conde de Nieva) el finiquito de rentas y otros impuestos en varias villas de Cáceres, La Rioja y Valladolid.

Ambos cónyuges (Leonor Niño de Portugal y Diego López de Zúñiga) se enterraron en la parroquia valverdeña de Santa María de Fuentes Claras, inicialmente en el coro del templo, como se dice en el testamento de Diego López de Zúñiga, otorgado en Valverde el 18 de noviembre de $1477^{19}$. En la citada fecha dispuso su sepultura y la distribución de sus bienes

"Don Diego López de Zúñiga, conde de Nieua y señor de la villa de Valberde, estando en mi seso natural e sano entendimiento e asimismo estando sano de las carnes sin ninguna pasión, ni enfermedad, enpero acordándoseme de la muerte que es cosa çierta e natural de la qual ninguna criatura no puede escapar e porque es cosa justta y razonable que todo hombre quando Dios le llamare para la otra vida para la qual fuimos criados esté dispuesto para andar aquel camino que no podemos escusar...".

Aunque no hay ninguna referencia al sepulcro monumental conservado, sí son muy interesantes y significativos algunos datos recogidos en el testamento, que iremos desgranando en nuestro estudio. Así, a finales de 1477 aún estaba Diego López de Zúñiga sano y no existía previsión del fallecimiento inmediato, hecho que sin duda se produjo a principios de la década de 1480 , considerando

17 Sobre el condado de Nieva, que tenía su cabecera en Nieva de Cameros, en la cuenca del río Iregua, véanse, entre otros trabajos, Alfonso Franco Silva, "Los dominios de los Velasco en tierras de La Rioja. El condado de Nieva (siglos XV-XVI)", en Os reinos ibéricos na Idade Media, Livro Homenagen al Professor Doutor Humberto Carlos Baquero (Oporto: 2002), 103-113, y Antonio Moreno Ollero, Los dominios señoriales de la Casa de Velasco en la Baja Edad Media (Sanlúcar de Barrameda: 2014).

18 Archivo Histórico de la Nobleza, NIEVA, C.1, D. 1, 20 de agosto de 1470/21 de noviembre de 1470.

19 Archivo Histórico de la Nobleza, ALTAMIRA, C.3,D.1: traslado del documento original otorgado el 18 de noviembre de 1477 ante el escribano de Valverde Juan Martínez del Portal, realizado por el escribano de Madrid Manuel de Matute el 10 de abril de 1726 por encargo de la Excma. Sra. Doña Ana Nicolasa de Guzmán Osorio Dávila Manrique de Zúñiga, Marquesa de Astorga, de Velada de San Román, Ayamonte y Villa Manrique, condesa de Sales y Nieva y Señora de Villatoro, entre otros títulos. No transcribimos el documento completo porque es muy largo y está digitalizado en pares.mcu.es, sólo hacemos referencia a aquellas partes del mismo que tienen interés para nuestro estudio. 
que probablemente nació a mediados del año 1404 porque sus padres se casaron en Pamplona el 26 de agosto de 1403.

Ordenó Diego López de Zúñiga en el testamento que

"mi cuerpo sea sepultado dentro, en el coro de la yglesia de Santa María de Fuenttes desta mi villa de Valberde junto con la sepultura de mi mui cara e amada muger doña Leonor Niño, que aya santa gloria ${ }^{20}$, a la mano derecha de su sepultura, e que sea puesto mi cuerpo en el ataúd en la manera siguiente: un jubón de armas bestido e unas calzas calzadas e atacadas y unas espuelas doradas labradas sin zapattos e debajo de la caueza una almuada...".

El "jubón de armas" citado, o almilla, era una prenda interior ajustada al busto como una camisola con faldones, sobre la que se colocaba la cota de malla o el peto de la armadura; solía tener mangas largas o cortas y podía ser una prenda muy rica, ornada con brocados. Las calzas cubrían la parte inferior del cuerpo, desde la cintura hacia abajo y solían ser ajustadas.

Además, dotó generosamente don Diego por su testamento dos capellanías en la "yglesia de Santa María de Fuenttes Claras desta dicha mi villa de Valberde, las capellanías mía e de la dicha doña Leonor Niño mi mui cara e amada mujer que aya santa gloria"; para ello legó 7.000 maravedíes anuales para cada uno de los capellanes, más sus correspondientes raciones de pan, vino y carne. En relación con lo anterior, ordenó el conde en el testamento que "de la zera de mis colmenas se cumplan las capellanías con sus velas a misa e a vísperas como yo lo e fecho después que la dicha mi muger falleszió". Confirmó don Diego en el mayorazgo a su primogénito y sucesor en el condado de Nieva, el mariscal Pedro de Zúñiga, al que legó también todos sus bienes y los de su difunta esposa, con la excepción de lo que dejaba a sus otros hijos: menciona especialmente a "Yñigo, mi fijo, su hermano", al que manda donar 150.000 maravedíes durante diez años — 15.000 cada año - y a "María de Vega, madre del dicho Yñigo" ${ }^{21}$, a la que concede, además, 4.000 maravedíes anuales más la ración diaria correspondiente. Ordena lo que había que entregar a otras personas, como los

20 Doña Leonor falleció el 9 de enero de 1469, según consta en la inscripción sepulcral que trascribimos más adelante. En 1467, estando gravemente enferma, hizo testamento a favor de su marido, ordenando que los enterraran juntos en donde él quisiera.

21 Yñigo tendría en este tiempo corta edad, pues nació sin duda tras el fallecimiento de la condesa; por eso los diez años que se citan en el testamento, tiempo en que su hermano Pedro tenía que mantenerlo, eran suficientes para que llegara a la mayoría de edad y pudiese escoger profesión, eclesiástica o no, según se dice en el repetido testamento. A Yñigo, además, le concedió unas casas en Villanueva y ordenó al mariscal "Pedro de Zúñiga mi fijo, que mire por el dicho Yñigo, mi fijo y su hermano, como la rrazón quiere" y "que siempre mire por la dicha María de Bega e la honrre por juntamiento que yo con ella e auido pues que en la honrra fallará que haze en ello su deuer". 
herederos del arzobispo de Braga, que era primo de su suegra "condesa". Por último encargaba encarecidamente el cumplimiento exacto de su testamento.

Son muy interesantes, por lo que luego diremos, las menciones expresas en el citado testamento al monasterio de Guadalupe, institución a la que don Diego dejaba 1.500 maravedíes para que rogaran por su alma y la de su esposa:

"Otrosí mando que den al monesterio de Guadalupe mill e quinientos marauedís porque rrueguen a Nuestro Señor Dios por mí e por la dicha doña Leonor Niño, mi muger".

También legó 100 ducados "para la obra desta yglesia desta dicha mi villa de Valberde", prueba evidente de que su construcción avanzaba, con la colaboración económica del conde, en la década de 1470. Precisamente a la parroquia entregó "una lámpara de plata (no conservada) que yo dejo fecha delante del Corpus Cristi" para que "arda continuamente" con el "azeitte de mis heredades". Quizá también de esta época o poco posterior data el espléndido cáliz gótico del último tiempo conservado en la parroquia, probable legado de los condes ${ }^{22}$.

Dato capital, a los efectos de intuir la autoría del sepulcro que analizaremos, es el nombramiento como albacea testamentario de don Diego (además de su primogénito Pedro de Zúñiga) del monje jerónimo guadalupano "devotto padre frai Juan de Yllescas, mi padre e confesor, profeso del Monesterio de Santa María de Guadalupe", para que, con licencia del prior del monasterio de San Bartolomé de Lupiana y "General Maior de la horden de Sant Gerónimo", "esecute e cumpla mi postrimera voluntad según dicho es". También declaraba don Diego que si Illescas fallecía al tiempo de "mi finamiento" que nombrase "otra persona de su horden... para que cumpla y esecute todo lo que él auía de cumplir y esecutar para que mi voluntad sea complida". Tal era la confianza que depositaba el conde en el padre Illescas, aún activo en el año $1500^{23}$, que en otra de las cláusulas del testamento expone lo siguiente:

22 Florencio-Javier García Mogollón, Viaje artístico por los pueblos de la Vera (Cáceres), $297-$ 298. Idem, "La platería de la Diócesis de Plasencia", en VIII Centenario de la Diócesis de Plasencia (11891989). Jornadas de Estudios Históricos (Plasencia: Caja de Ahorros,1990),166.Florencio-Javier García Mogollón (director), Inventario artístico de Cáceres y su provincia. Tomo I. Partidos judiciales de Alcántara y Cáceres y comarca de la Vera de Cáceres (Madrid: Ministerio de Cultura, Instituto de Conservación y Restauración de Bienes Culturales, 1990), 427.

23 Fray Juan de Illescas, en tiempos del prior Pedro de Vidania y con sus poderes, protestó en apelación el 10 de noviembre de 1500, ante el Vicario General de Cisneros y el notario público apostólico Juan Porcel, el subsidio de 5.000 maravedíes impuesto por el Cardenal al Monasterio de Guadalupe. Es evidente que Illescas era persona muy relevante y apreciada en el monasterio, cuando le encargaban asuntos tan delicados. Véase Carlos G. Villacampa, Grandezas de Guadalupe. Estudios sobre la historia y las bellas artes del gran monasterio extremeño (Madrid: Imprenta de Cleto Vallinas, 1924), 138. 
"Mando que den a mi padre e confesor frai Juan de Yllescas cinquenta mill marauedís para los gastar y dar en ziertos lugares que con él yo tengo fablado de que tengo cargo".

Ello nos habla de las relaciones intensas y frecuentes del conde de Nieva, que tenía ya muy presente la idea de la muerte, con el monasterio de Guadalupe y con su comunidad jerónima; precisamente en la década de 1470 el notable escultor Egas Cueman trabajaba en el monumento funerario de los Velasco ${ }^{24}$, en el de Fernando Álvarez de Meneses (1478) y en otras obras del monasterio, para el que dicho artista ya había realizado el sepulcro del obispo jerónimo don Gonzalo de Illescas ( $\uparrow 1464)$, contratado el 5 de noviembre de 1458. Opinamos, como más adelante desarrollaremos, que estas relaciones no son casuales sino más bien causales en conexión con la sepultura valverdeña, probablemente labrada en la década de 1480 por el citado artista.

Luego se trasladarían los restos mortales del matrimonio, por orden de su hijo Pedro, desde sus iniciales y modestas sepulturas en el coro al lujoso sepulcro objeto de nuestro estudio; la empresa trujillana Restaura S.L., a instancias de la Junta de Extremadura, clasificó y limpió los elementos conservados del mismo desde el mes de agosto de 2017 con la intervención de la restauradora Rocío Pardo Moreno; lo que permanece del sepulcro se ha recompuesto en la capilla lateral del templo; la obra final se readjudicó en junio de 2018 y se terminó en 2019.

El edificio parroquial de Santa María de Fuentes Claras, en el que permanece el sepulcro que nos ocupa, es una notable construcción de tres naves, separadas por esbeltos pilares columnarios que soportan elegantes arcos formeros pometeados y cubierta de madera. El edificio se reformó hace algunos años, perdiendo la cubierta viejas vigas de madera policromadas con motivos renacentistas que alcanzamos a ver y catalogar, y aprovecha, como dijimos, diversos elementos del castillo: la torre de los pies de la iglesia, que hace funciones de campanario, el torreón-camarín adosado a la cabecera (en el que permanece la interesante talla de la patrona del templo, obra gótica de influencia flamenca de mediados del siglo XV) y el ábside de planta exagonal con arcaica bóveda de crucería octopartita timbrada en su clave con el escudo de los Zúñiga; en el citado torreón-camarín y en el ábside se aprecian huecos a modo de almenas,

24 Alonso de Velasco, casado con Isabel de Quadros, era hijo de Juan Fernández de Velasco, emparentado con los condestables de Castilla y condes de Haro, y su madre, María de Solier, era hija de Arnao de Solier, notable personaje navarro luego establecido en Castilla. Es posible que los Zúñiga, asimismo navarros, fueran influidos por esta familia, a través de su documentada conexión guadalupana, para contratar a Egas Cueman. 
algunos tapiados, y saeteras que manifiestan una anterior utilización militar. El templo actual se iniciaría, quizá sobre uno precedente más pequeño, en la segunda mitad del siglo XV y estaba terminado en sus partes esenciales en la cuarta década de la centuria siguiente. Colaboraron en la financiación de las obras los condes de Nieva, como se deduce de la ayuda económica citada y de los escudos de los Zúñiga y Velasco presentes en la capilla mayor, antiguo edificio de la vecina fortaleza como dijimos. Todo ello justifica el estilo hispanoflamenco que predomina en los elementos decorativos, entre los que abundan los pometeados ${ }^{25}$.

Al respecto del citado ábside, digamos que en la documentación del siglo

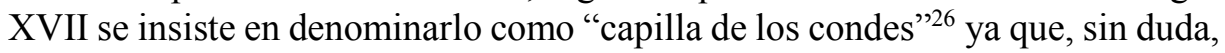
su sepulcro se disponía, exento, en un lugar preferente de la misma; parece que dicha capilla mayor parroquial, que formó parte del castillo, la donó para el enterramiento de sus abuelos Francisca de Zúñiga en los años finales del siglo $\mathrm{XV}^{27}$. No obstante, quizá los cuerpos estuvieron enterrados en la cripta subteránea que tiene el templo en su cabecera, descubierta en enero de 1807 cuando se colocaban losas nuevas en la capilla mayor ${ }^{28}$. Por eso el hermoso sepulcro que analizaremos era seguramente un cenotafio.

Cuando vimos el sepulcro por primera vez, a finales de la década de 1970, estaba desordenado - separados los esposos - en dos hornacinas o lucillos de medio punto, quizá con función funeraria, existentes en los lados del ábside, circunstancia que confundió a Fernández Oxea, que creyó que los bultos representaban a dos damas, madre e hija ${ }^{29}$; ya entonces opinábamos que los cónyuges reposaron originalmente juntos en un solo monumento funerario, luego

25 Más datos se localizan en Florencio-Javier García Mogollón, Viaje artístico por los pueblos de la Vera, 285 y ss. Véase, también, Florencio-Javier García Mogollón (director), Inventario artístico de Cáceres y su provincia. Tomo I, 421 y ss.

26 Florencio-Javier García Mogollón, Imaginería medieval extremeña. Esculturas de la Virgen María en la provincia de Cáceres (Cáceres: UEx-Edit. Extremadura, 1987), 170.

27 Francisca López de Zúñiga casó con Antonio de Velasco (†1523), cuyos escudos policromados decoran la capilla mayor junto a los de Zúñiga. El hijo mayor de ambos, Diego López de Zúñiga y Velasco, fue virrey del Perú (1561-1564). Sin embargo, en el testamento y codicilo de Francisca, otorgado en Burgos el 2 de mayo de 1523, en el que enmienda algunas cosas del testamento de su fallecido esposo, no se dice nada al respecto de la capilla mayor. Véase Archivo Histórico de la Nobleza, ALTAMIRA, C.3, D.23.

28 José Ramón y Fernández Oxea, "Iglesias cacereñas no catalogadas", Revista de Estudios Extremeños XVI, 1 (1960): 68.

29 Fernández Oxea supone erróneamente que una de las “damas” es doña Catalina de Zúñiga, VII señora de Valverde, y la otra una hija suya; menciona, además, unas inscripciones inexistentes en los libros que portan los bultos funerarios. José Ramón y Fernández Oxea, "Iglesias cacereñas no catalogadas", 6970. 
desbaratado y troceado bárbaramente ${ }^{30}$. Quizá el destrozo se produjo con motivo de la ocupación francesa de la comarca ${ }^{31}$ : los franceses se acantonaron en Valverde desde el 28 de julio hasta el 8 de septiembre de 1811 y utilizaron como cárcel el templo parroquial, teniéndose que celebrar los oficios en la ermita de Cristo de Humilladero ${ }^{32}$. También pudiera ser que el sepulcro fuera desarmado cuando se remodeló el presbiterio parroquial para colocar el nuevo retablo mayor en 1704 .

Los esposos están recostados en el mismo lecho, don Diego a la derecha y dona Leonor a su izquierda, posición recuperada en la presente restauración, aunque faltan piezas, y a la que se alude en el mencionado testamento de don Diego. Los cónyuges no se miran mutuamente, sino que giran hacia el espectador sus rostros - retratos de los finados-, el conde como un anciano de huesudos pómulos y visibles arrugas y más idealizada y joven la condesa. El lecho se alza sobre una especie de catafalco marmóreo constituido por placas rectangulares bellamente labradas, varias perdidas, elevadas sobre un pedestal en forma de escocia lisa, con una banda superpuesta que adornan ondulantes tallos con hojas de vid a modo de cardinas, racimos y animales fantásticos. Dichas placas muestran una rica decoración vegetal y de animales monstruosos, propia del gótico final y similar a la desarrollada por Cueman y su escuela en la puerta de los Leones de la Catedral toledana, en San Juan de los Reyes o en el palacio del Infantado de Guadalajara: se observan dragones alados sobre ramas de encina con bellotas, seres humanos abrazados a tallos arbóreos, piñas, hojas de vid, abultadas cardinas y otros elementos vegetales inscritos en orlas angreladas; todo ello está deliciosamente labrado en un alabastro de excelente calidad que, debido a la finura de la talla y a sus propiedades translúcidas, a veces crea curiosos y bellos efectos lumínicos. Y precisamente el alabastro era un material predilecto de Cueman, pues en el contrato del sepulcro del obispo Illescas se afirma que Cueman se obligó a hacer "un bulto de alabastro bueno e fino e blanco"33. Es sorprendente, por otra parte, el gran parecido de algunos de los citados ornamentos, sobre todo las piñas encerradas en orlas, con el de las ricas telas bordadas del Descendimiento de Rogier van der Weyden custodiado en el

30 Florencio-Javier García Mogollón, director, Inventario Artístico de Cáceres y su Provincia. Tomo I, 425: aunque la publicación data de 1990, los trabajos de campo y toma de datos se realizaron entre los años 1977 y 1978.

31 Incendiaron y saquearon el monasterio de Yuste en el mes de agosto de 1809, cuyo incendio afectó sobre todo a los claustros y especialmente al renacentista. Florencio-Javier García Mogollón, Viaje artístico por los pueblos de la Vera, 148-149.

32 José Ramón y Fernández Oxea, “Iglesias cacereñas no catalogadas”, 68-69.

33 Germán Rubio e Isidoro Acemel (con introducción de Elías Tormo), "La escultura española en el siglo XV. El maestro Egas en Guadalupe”, Boletín de la Sociedad Española de Excursiones, 20 (1912): 200 . 
Prado, prueba evidente de que el escultor conocía bien la obra del citado pintor y los lujosos tejidos de Flandes. Remata el catafalco una banda con geométricos tallos entrelazados y pequeñas hojas.

El conde, cuyo rostro muestra graves daños (nariz rota, pómulos, ceja izquierda, labio superior y ojos picados), está tocado con una especie de turbante anudado sobre la frente y cubre la camisa con unas vestiduras a modo de sayo, ricamente decoradas con motivos vegetales propios de la época, similares, por ejemplo, a los que muestran la figura taraceada de la reina Isabel la Católica que preside la sillería coral de la Catedral de Plasencia o diversas obras de Rogier van der Weyden, como el citado Descendimiento del Museo del Prado (h. 1442). Don Diego se abriga de cintura hacia abajo con el embozo de la ropa de cama, exquisitamente labrada imitando la estructura textil. A los pies se observa el remate de la colcha, adornado con una faja de rosetas de cuatro pétalos con botón central.

Porta el conde de Nieva en sus manos, al igual que su esposa, un libro abierto sobre el que quizá medita los textos del Nuevo Testamento relacionados con la resurrección y con la vida eterna. Se puede conectar simbólicamente el libro con el Libro de la Vida citado en el Apocalipsis (3, 5;13,8;17,8; 20,15; 21,27). También se menciona el Libro de la Vida en Éxodo (32,32-33), Salmos $(56,9 ; 69,29 ; 139,16)$, Daniel $(12,1)$, Malaquías $(3,16)$, Lucas $(10,20)$ y epístolas de San Pablo, Filipenses (4,3) y Hebreos (12,23), entre otros. En el Libro de la Vida están inscritos los que son considerados justos ante Dios, mientras que muere para siempre el que es borrado de sus páginas. También el libro abierto simboliza los misterios divinos que se transmiten a quien lo lee. En cualquier caso, este libro espiritual que portan en sus manos los yacentes se relaciona con la transcendencia del alma y con la vida eterna que espera todo cristiano. Puede aclarar esta cuestión una frase incluida en el contrato (1467) de Cueman para realizar el sepulcro guadalupano de los Velasco, que contenía dos libros abiertos delante de los difuntos, quienes habían de estar "conmo si estouiesen resando por los dichos libros con las manos juntas e bien puestas cerca dellos"34.

También se observan deterioros en el bello y sereno rostro de doña Leonor, aunque son menores que los de su esposo: tiene la nariz y los labios picados. Se cubre con unas tocas monjiles con pliegue angular superior idéntico al que muestra la Virgen del Santo Entierro conservada en el Monasterio de Guadalupe, obra de Cueman, y la ropa, más sencilla que la de su marido, muestra una orla vegetal en el pecho y aberturas laterales en el corpiño. Sorprende la utilización

34 Germán Rubio e Isidoro Acemel, "La escultura española en el siglo XV”, 207. Dichos libros desaparecieron del sepulcro guadalupano en fecha desconocida. 
de dos tocas superpuestas y la manera como se disponen sobre la cabeza y rostro, pues se sigue al pie de la letra la disposición ordenada por Cueman en el contrato citado del sepulcro de los Velasco en lo referido al bulto de Isabel de Quadros:

"tocada de dos tocas llanas, una más baxa que llegue cerca de las cejas e la otra un poco más alta o amas (sic) a dos que lleguen cerca de los onbros en tal manera que non cubran mucho el manto; e ha de tener un reboço por debaxo de la barua en tal manera que cubran bien la garganta e la barua quede descubierta" 35 .

Una especie de pequeña manta de lana abriga la cintura de doña Leonor, que tiene en sus finas manos, deliciosamente labradas, como las del conde, un libro abierto según dijimos: con el dedo índice de la mano derecha señala una parte de la página impar.

A los pies del conde reposa una deliciosa perrita. En la escultura funeraria cristiana es frecuente, desde el siglo XIII, situar un perro junto al finado: el detalle simboliza la vigilancia, lealtad, fidelidad (viaje de Tobias, 5,16) y confianza en Cristo, siendo además el perro, en varias culturas, acompañante (psicopompo) del espíritu de los muertos en su viaje al más allá, tras haber sido fiel compañero durante la vida en la tierra. Eso ocurre en la tradición germánica, que relaciona al perro Garm con la vida de ultratumba y con la resurrección, en la cultura egipcia, en la que Anubis es guía del difunto hasta ser juzgado por Osiris, o en varias culturas mesoamericanas, en las que el perro Xolotl también conduce al difunto al inframundo. En nuestro caso guarda la paz eterna de los yacentes una perrita de orejas caídas y muy naturalista, con incisiones en algunas partes de su cuerpo para simular el pelaje y con las patas delanteras cruzadas: tiene gran concomitancia con el perro macho del sepulcro del obispo Barrientos, que mencionamos más adelante, aunque a la figura de Valverde le falta el ancho collar sujeto por fuerte traba presente en el primero que, por otra parte, tiene quebradas las patas delanteras.

Es claro que el virtuosismo de la obra, los exquisitos detalles decorativos relacionados con lo flamenco y las coincidencias con las citadas piezas guadalupanas, hablan por sí mismos de la intervención de un escultor de primera fila que, a nuestro juicio, ha de ser Egas Cueman como ya hemos avanzado. Es un encargo suntuoso, realizado por una familia noble de gran relevancia, prestigio y poder económico en la España de su tiempo que, precisamente por eso, quiso perpetuar eternamente su aristocrático linaje terreno por medio de una sobresaliente pieza artística que enlaza con la idea cristiana de transcendencia. Así, el

35 Germán Rubio e Isidoro Acemel , "La escultura española en el siglo XV”, 207. 
lujoso sepulcro terrenal es un símbolo de la vida en el paraíso. Creemos que la calidad escultórica de Cueman dejó claros estos conceptos en la excelente obra valverdeña. En cuanto a su costo, no poseemos datos, pero pueden servir como referencia los 16.000 maravedíes en que se contrató en 1458 el citado sepulcro guadalupano de Gonzalo de Illescas: al menos habría que duplicar la cantidad, considerando que el sepulcro valverdeño se fabricó en la década de 1480, tiene mayor tamaño y dos estatuas yacentes.

Con motivo de la limpieza y restauración del sepulcro hemos podido leer, con alguna dificultad, debido a los deterioros, las dos inscripciones descubiertas en la parte posterior de los almohadones sobre los que reposan las cabezas de los condes; epígrafes escritos en bellos caracteres góticos, de los que teníamos noticias por la transcripción antigua de López de Haro, pero que se creían perdidos. Las transcribimos más abajo y aprovechamos para anotar algunos datos históricos sobre los personajes citados en ellas. Sujetan los almohadones, en los laterales, un paje y una doncella, arrodillados y lamentablemente decapitados.

En los almohadones de la condesa doña Leonor Niño, se lee:

“AQUÍ YASE LA MUY NO/
BLE SEÑORA DE LOABLE/
MEMORIA DOÑA LEO/
NOR NINO CONDESA DE/
NIEUA E SEÑORA DES/
TA UILLA DE UALUER/
DE HIJA DE LOS MAGNIFICOS/
SEÑORES DON PEDRO NINO/
CONDE DE BUELNA E CONDE/
SA DONA BEATRIZ SU MU/
JER UISNIETA DE LOS RE/
IES DE CASTILLA DON ENR/
IQ(ue) E DE DON PEDRO REI/
DE PORTOGALO TODO/
DE LEXITIMO MATRIMO/
NIO FALLECIO IX DIAS/
DE ENERO AÑO DE LXIX”

Lo señalado en letra cursiva no se lee bien, en parte por el desgaste que ha sufrido el alabastro, desconchado hacia el final de la inscripción; además, la zona en la que se incluye la fecha también tiene desperfectos, siendo visible una rotura triangular. No obstante, creemos haber realizado una transcripción 
correcta, manteniendo la ortografía original y corrigiendo a López de Haro. La inscripción se refiere a los padres de doña Leonor, don Pedro Niño, conde de Buelna $^{36}$, y doña Beatriz de Portugal ${ }^{37}$. También se nombra a sus abuelos, el rey don Pedro I de Portugal (1320-1367), enterrado en un lujoso sepulcro en el monasterio de Alcobaça frente al de doña Inés de Castro, y el rey don Enrique II de Castilla (1333-1379).

En los almohadones del conde, don Diego López de Zúñiga, se lee:

\author{
“AQUÍ YASE (picado el alabastro) \\ EL MUY NOBLE E M/ \\ AGNIFICO SEÑOR DON DI/ \\ EGO LOPES DESTUNIG/ \\ A CONDE DE NIEUA/ \\ E SENOR DE ESTA UYLL/ \\ A DE UALUERDE NIETO DEL/ \\ REI DON CARLOS DE N/ \\ AVARRA DE LEGITIMO MATRI/ \\ MONIO E DE DIEGO LOPES DESTU/ \\ NIGA IUSTICIA MAIOR DE CA/ \\ STILLA FIJO DE INIGO ORTIZ DE/ \\ STUNIGA E DE LA INFANTA D/ \\ ONA IUANA DE NAUARRA SU MUGER"
}

Lo señalado en cursiva, como en el caso anterior, se lee mal por los deterioros del alabastro. No obstante, se intuye.

36 Pedro Niño (1378-1453), conde de Buelna (título concedido por Juan II) y señor de Cigales, fue un destacado militar y marino, cuyas hazañas, como las varias derrotas que infligió a la armada inglesa, se recogen en Gutierre Díez de Games, El Victorial: Crónica de don Pedro Niño, conde de Buelna (h. 1436), manuscrito de la Biblioteca Nacional de España, MSS/17648. Véase, también, Eugenio Llaguno y Amirola, Crónica de don Pedro Niño, conde de Buelna, por Gutierre Díez de Games, su alférez (Madrid: Imprenta de Antonio de Sancha, 1782), Rafael Beltrán Llavador, Un estudio sobre la biografia medieval castellana: la realidad histórica de Pero Niño y la creación literaria de "El Victorial" (Valencia: Universidad, 1987) e ídem (edición, estudio y notas), Gutierre Díez de Games, El Victorial (Madrid: RAE, 2014). Consúltese, asimismo, Alonso López de Haro, Nobiliario Genealógico de los Reyes y Títulos de España (Madrid:1622), libro IV, cap. VIII, 209-211.

37 Beatriz de Portugal (1382), llamada Isabel Brites de Borgoña, era hija del Infante don Juan de Portugal (Borgoña), duque de Valencia de los Campos, y de Constanza Enríquez de Castilla, señora de Alba de Tormes. Véase César Olivera Serrano, Beatriz de Portugal y la pugna dinástica Avis-Trastámara (Santiago de Compostela: CSIC, 2005), 288. 
Según López de Haro ${ }^{38}$ el título del condado de Nieva unos lo datan en 1469 y otros en 1473, pero está claro que lo concedió Enrique IV (quizá en 1466) y que ya existía en el primero de los años indicados, considerando la fecha que figura en la inscripción del sepulcro valverdeño, y, desde luego, en 1470, según apuntamos más arriba. Por ello el personaje retratado en el sepulcro que estudiamos, Diego López de Zúñiga, fue el primer conde de Nieva, según se refleja, además, en la documentación conservada en el Archivo de Simancas ${ }^{39}$. López de Haro cita la inscripción con algunos errores de transcripción, al igual que Antonio Valladares de Sotomayor ${ }^{40}$.

El viejo y poderoso linaje de los Zúñiga, Estúñiga o Stúñiga ${ }^{41}$ radica en la villa navarra de Zúñiga (Valle de la Solana, merindad de Estella), localidad natal de Íñigo Ortiz de Zúñiga y Leiva -citado en el epígrafe sepulcral como padre del primer conde de Nieva y Señor de Valverde-, quien parece que fue el autor de parte de las coplas de iAy Panadera!, que generalmente se consideran anónimas y que ironizan sobre la bochornosa y cobarde actitud de la nobleza castellana en la batalla de Olmedo $(1445)^{42}$. Es curioso que en dichas coplas se mencione varias veces a $\mathrm{La} \mathrm{Vera}{ }^{43}$.

La infanta doña Juana de Navarra, mencionada en la inscripción sepulcral como madre de nuestro conde, era hija natural del rey navarro don Carlos III el Noble, nieta del rey Carlos V de Francia ${ }^{44}$, señora de Eslava y Sada y casó efectivamente, según manifiesta el repetido epígrafe, con el mariscal Íñigo Ortiz de Stúñiga y Leiva, primer señor de Lacarra, hijo del Justicia Mayor de Castilla Diego López de Estúñiga: los desposorios se celebraron en Pamplona el 26 de agosto de 1403. Las capitulaciones matrimoniales se habían firmado en el Palacio Real de Olite ante el secretario y notario del rey don Carlos III el 8 de marzo

38 Alonso López de Haro, Nobiliario Genealógico de los Reyes y Títulos de España, I, cap. XXII, 565 .

39 Máximo Diago Hernando, "Linajes Navarros en la vida política de la Rioja. El ejemplo de los Stúñiga”, Príncipe de Viana Año 53, no 197 (1992):575, nota 52: menciona un documento datado en el mes de noviembre del año 1477 conservado en el Archivo General de Simancas, Registro General del Sello.

40 Antonio Valladares de Sotomayor, Semanario erudito, que comprehende varias obras inéditas, crí-ticas, morales, instructivas, politicas, históricas, satíricas y jocosas de nuestros mejores autores antiguos y modernos (Madrid: Blas Román, 1790), vol. XXIX, 51.

41 Entroncan los Zúñiga directamente con Íñigo Arista, considerado como el primer rey o caudillo de Pamplona. Véase Pedro Manuel Cátedra García, La "Historia de la Casa de Zúñiga" otrora atribuida a Mosén Diego de Valera (Salamanca: Seminario de Estudios Medievales y Renacentistas, 2003).

42 Sobre las coplas véase Julio Rodríguez Puértolas, Poesía crítica y satírica del siglo XV (Madrid: Castalia, 1989).

43 "Cómo te fue allá en la Bera, ay panadera", o "Panadera, soldadera, que vendes pan de barato, cuéntanos algún rebato que te aconteció en la Vera".

44 Valladares de Sotomayor, Semanario erudito, XXIX, 51. 
de 1396 y en ellas se cita a "Íñigo Ortiz de Estúñiga, hijo legítimo de Diego López de Estúñiga, Justicia Mayor del Rey de Castilla"45 y miembro del Consejo de Regencia: se refiere, sin duda, a la regencia por la minoría de edad de Enrique III. En dichas capitulaciones se hacía la observación de que se casarían cuando tuvieran la edad adecuada para ello y, además, se estipulaba que el rey navarro entregaría una dote de 10.000 florines de oro de Aragón y la misma cantidad entregaría Diego López de Estúñiga ${ }^{46}$. De este matrimonio fue hijo primogénito el primer conde de Nieva y señor de Valverde retratado en el bulto funerario.

La relevancia y alcurnia de los linajes de ambos personajes, entroncados por vínculos de sangre con la realeza portuguesa, castellana, navarra y francesa ${ }^{47}$, tiene que estar necesariamente en consonancia con la importancia del artista autor del monumento que, a nuestro juicio, no es otro, como ya hemos dicho, que el flamenco avecindado en Toledo Egas Cueman.

\section{$* * *$}

Quizá encargó el sepulcro Pedro de Zúñiga, segundo conde de Nieva, primogénito de los condes que casó con Blanca Enríquez de Monroy y Herrera. Parece claro que se realizó en los inicios de la década de 1480, quizá cumpliendo la voluntad de sus padres, Diego López de Zúñiga y Leonor Niño de Portugal, aunque en el testamento mencionado no aparece ningún dato al respecto.

El estilo de nuestro sepulcro y la riqueza de los ropajes recuerdan los detalles decorativos del bulto funerario del obispo Lope de Barrientos (1447-1454), atribuido a Egas Cueman por su excepcional calidad. Barrientos (1382-1469) fue un notable personaje de la época, confesor y consejero de Juan II de Castilla, obispo de Ávila, Cuenca y Segovia, Inquisidor y Canciller Mayor de Castilla y al que citan las coplas de iAy panadera! como combatiente en la batalla de Olmedo. La escultura se conserva en el Museo de las Ferias de Medina del Campo (Valladolid) y durante el año 2015 estuvo en la exposición que el Museo del Prado dedicó a Rogier van der Weyden. El perro que reposa a los pies del prelado

45 Se referirá a los reyes castellanos don Juan I (1379-1390) o a su sucesor Enrique III el Doliente (1390-1406).

46 Véanse todos estos particulares en Juan Agapito y Revilla, "Casamiento de doña Juana de Navarra, hija natural de don Carlos III el Noble, con Íñigo Ortiz, hijo de Diego López de Estúñiga, justicia mayor del Rey de Castilla", Boletín de la Real Academia de la Historia LXXXI (noviembre de 1922): 383-414 y, especialmente, 386-87.

47 El conde, en su citado testamento, se refiere al abolengo de los ascendientes familiares cuando detalla, con pena, el mal trato que su yerno Alfón de Monroy, hijo de Fernando de Monroy y señor de Belvís, daba a Beatriz de Zúñiga, su hija, "apartada de sí e la a tratado e trata en gran mengua mía e suya non mirando quien ella es e del linaje donde biene..." 
es similar a la perrita del sepulcro de Valverde, como dijimos, y también se parecen los pormenores de los suntuosos ropajes. Incluso las borlas del cojín sobre el que se arrodilla el obispo, con flecos y esfera granulada, son sospechosamente idénticas a las que portan los almohadones de nuestro sepulcro valverdeño. El sepulcro de fray Lope de Barrientos se data entre los años 1447 y 1454 , siendo así la primera obra documentada en el tiempo de Cueman ${ }^{48}$.

En relación a las almohadas y borlas del monumento de Valverde, sorprende la analogía con lo que se dice en el contrato suscrito entre Cueman y don Alonso de Velasco para labrar su sepulcro guadalupano, otorgado ante el escribano González Gigante el 12 de septiembre de $1467^{49}$ :

"e las almohadas asymesmo han de tener sus botones e borlas e franjas al derredor e encima dellas ha de uenir en derecho de cada bulto un libro abierto con sus coberturas de seda con sus borlas e botones a los cantos".

También hay referencias en el expresado contrato a la riqueza de los ropajes, pues al referirse a los ángeles que flanquean la entrada a la capilla de Santa Ana, en donde se encuentra la sepultura, se dice que habían de estar

"vestidos con sus aluas e almáticas de damasco con sus qruses e los redropios $^{50}$ e bocas de las mangas de brocado".

Los padres Rubio y Acemel, estudiosos de la obra de Cueman en Guadalupe, también detallaron la riqueza de las vestiduras en las esculturas de Egas cuando analizaron el sepulcro del obispo Gonzalo de Illescas visible en el claustro del monasterio: "los hermosos plegados del ropaje de la estatua", el "labrado admirable del bordado con que se halla todo el hermoso pontifical que viste el señor obispo lujosamente recamado", la "finura de la ejecución en todos sus detalles" ${ }^{51}$. Todo ello es aplicable a la suntuosidad de los ropajes de los condes de Nieva en Valverde. Es una ornamentación de extraordinaria riqueza, que imita a partir de elementos vegetales los brocados de la época, la que muestra el bulto yacente del obispo de Córdoba fray Gonzalo de Illescas, cuyo sepulcro, maltratado, se realizó por un dibujo del notable platero jerónimo fray Juan de Segovia con los cambios que sin duda introdujo Cueman: parece evidente la vinculación de

48 Sobre el sepulcro de Barrientos y Egas Cueman, véase Lorne Campbell y José Juan Pérez Preciado, Rogier van der Weyden y los reinos de la Península Ibérica (Madrid: Museo del Prado, 2015), 166-172.

49 Germán Rubio e Isidoro Acemel, "La escultura española en el siglo XV”, 192-229. Dichas borlas son también muy parecidas a las del sepulcro de Gonzalo de Illescas, cuestión en la que insistimos más adelante.

50 Rodopio o redopio, palabra de origen portugués que significa girar, rotar, y que, en este caso, se referirá a las vueltas de las vestiduras o de las mangas.

51 Germán Rubio e Isidoro Acemel , "La escultura española en el siglo XV", 202. 
Illescas y Barrientos, ambos prelados importantes personajes en la corte de Juan II, consejeros y confesores del monarca, por lo cual no es difícil admitir la intervención de un mismo artista, Egas Cueman, para labrar los dos sepulcros ${ }^{52}$. Por cierto, la cabeza de Illescas reposa sobre dos almohadones, como en Valverde las testas de los condes, las borlas de los mismos son sospechosamente idénticas a las presentes en Valverde y en el sepulcro de Barrientos y las cardinas que adornan diversas partes de la pieza son similares a la ornamentación vegetal visible en las placas conservadas del sepulcro valverdeño, que formaban los laterales del lecho funerario, hoy en parte deteriorados y con dificultades, por tanto, para su completa reconstrucción y montaje. Además, la disposición de dichas placas es similar en ambos sepulcros, el de Valverde y el de Guadalupe.

Más sobrios son los ropajes de don Alonso de Velasco y su esposa en el citado sepulcro guadalupano ${ }^{53}$, como austeras son las vestiduras de los personajes de las estaciones del Vía Crucis del monasterio extremeño, obras estas de madera policromada atribuidas a Egas y en las que son evidentes las influencias de van der Weyden que ya apuntamos hace años ${ }^{54}$ y que también se observan en el diseño de los ángeles del sepulcro de los Velasco y en el plegado de sus ropajes.

Es curiosa, por otra parte, la relación entre el sepulcro valverdeño y el de Martín Vázquez de Arce, el Doncel de Sigüenza, como ya manifestara Fernández Oxea ${ }^{55}$; tanto el doncel como los condes de Nieva leen un libro que estos portan abierto entre sus manos, por lo cual se incorporan ambos, como el doncel, sobre el lecho en el que yacen; además, un pajecillo se dispone a los pies de don Martín, paje y doncella que en Valverde sostienen los almohadones sobre los que reposan las testas de los difuntos. El sepulcro de Sigüenza, cumbre de la escultura gótica española del último tiempo, se atribuye al importante escultor con taller en Guadalajara Sebastián de Almonacid o de Toledo, influido por

52 Véase el actualizado trabajo de Ángel Fuentes Ortiz, "La capilla de Gonzalo de Illescas en el Monasterio de Guadalupe: un proyecto de Egas Cueman recuperado", Archivo Español de Arte XC, 358 (2017): 107-124.

53 El monumento se policromó posteriormente, quizá con la intervención de Cueman. Aunque la policromía se perdió sabemos que incluía ricos elementos ornamentales, como consta en un memorial de Isabel de Quadros conservado en el Archivo del Monasterio de Guadalupe: Germán Rubio e Isidoro Acemel, "La escultura española en el siglo XV", 213 y ss.

54 Florencio-Javier García Mogollón, Imaginería medieval extremeña, 104-105. Véase, también, Florencio-Javier García Mogollón, "Cultura y evangelización. Aproximación a la iconografía de la Pasión de Cristo en el arte extremeño", Cauriensia X (2015): 136 y 141.

55 Ramón y Fernández Oxea, "Iglesias cacereñas no catalogadas", 70: "las dos estatuas son verdaderas obras de arte... y ambas recuerdan la del doncel, Martín Vázquez de Arce, de la Catedral de Sigüenza, con la que presentan analogías, no sólo en la disposición y en la ejecución, sino también en los detalles, como el del pajecillo..." 
Cueman a través del obrador toledano de San Juan de los Reyes y por su intervención en el palacio de los Duques del Infantado en la misma Guadalajara. Por eso el sepulcro del doncel es una consecuencia de la escuela de Egas Cueman, en íntima conexión con la obra escultórica de San Juan de los Reyes, de cuya fábrica fue maestro de escultura (1479-1484) ${ }^{56}$, así como también está en relación con la estatuaria de la portada de los Leones de la Catedral toledana (14521465) y con la obra decorativa del citado palacio del Infantado.

El profesor Azcárate Ristori sitúa la ejecución del sepulcro seguntino a principios de la década de 1490, considerando que el doncel falleció durante la guerra de Granada en $1486^{57}$. Además, como con acierto observa Azcárate, el sepulcro del Doncel respeta en líneas generales, con algunas diferencias, el esquema concebido por Egas Cueman (h. 1465) para el primer proyecto de la tumba ya citada de don Alonso de Velasco en el Monasterio de Guadalupe ${ }^{58}$; esquema que no mantuvo Egas cuando ejecutó definitivamente la obra guadalupana: su idea inicial era la de disponer los sepulcros de los esposos (Alonso de Velasco e Inés de Quadros) de manera independiente y con las estatuas yacentes, aunque finalmente determinó situarlos juntos y arrodillados en oración; no obstante, dicho diseño inicial sirvió para que el propio Egas, o un discípulo, trazase los sepulcros del I Conde de Tendilla, D. Íñigo López de Mendoza, y su mujer Doña Elvira de Quiñones, hoy en la iglesia de San Ginés de Guadalajara, obras que debieron de esculpirse en torno a 1480 o poco después ${ }^{59}$.

Parece evidente la relación señalada por el profesor Azcárate si observamos detenidamente las trazas del primer proyecto guadalupano para el sepulcro de don Alonso de Velasco que, sin duda, como dicen Rubio y Acemel, es posterior a 1464 y anterior a 1467, pues el sábado 12 de septiembre del último año citado se formalizó, como dijimos, el contrato definitivo para la realización de la obra (terminada hacia 1476) ante el escribano González Gigante. Ese primer proyecto, firmado por Egas, dibuja los sepulcros independientes de los esposos: sólo se conserva el de don Alonso, pero el de su esposa Isabel de Quadros sería idéntico, salvo el bulto funerario; cuyos dibujos, tres, se custodian en el Museo del Monasterio. En el dibujo principal se diseña un arcosolio de medio punto angrelado, coronado por una hornacina trilobulada en la que un ángel, flanqueado a su vez

56 José María de Azcárate Ristori, "Sentido y significación de la arquitectura hispano-flamenca en la corte de Isabel la Católica", Boletín del Seminario de Estudios de Arte y Arqueología de la Universidad de Valladolid XXXVII (1971): 222-223.

57 José María de Azcárate Ristori, "El maestro Sebastián de Toledo y el Doncel de Sigüenza”, Wadal- Hayara: revista de estudios de Guadalajara 1 (1974): 26.

58 De Azcárate Ristori, "El maestro Sebastián de Toledo y el Doncel", 12.

59 De Azcárate Ristori, "El maestro Sebastián de Toledo y el Doncel", 12. 
por otros ángeles, lee un libro, quizá simbólico del Libro de la Vida ${ }^{60}$. En esa traza inicial (rubricada "Egas Cueman" ${ }^{161}$ ) tiene gran interés el diseño de la estatua yacente de don Alonso, miembro que fue del Consejo Real, pues se lo presenta, con su espada, ligeramente incorporado del lecho, con la cabeza cubierta con un bonete y apoyada en un almohadón doble (como en Valverde), con las manos unidas y la mirada vuelta al espectador, en una posición muy parecida, por no decir idéntica, a la del bulto funerario de Valverde; sostienen la cama, muy alta, como la de Valverde, tres leones y en su basamento (no en la parte superior) falta la menuda ornamentación valverdeña, sustituida por el escudo central tenido por ángeles ${ }^{62}$. Ornamentación vegetal y de animales fantásticos que es característica del taller de Cueman, como ponen de manifiesto el sepulcro finalmente realizado en Guadalupe y los detalles presentes en San Juan de los Reyes o en la portada de los Leones de la catedral toledana, según ya hemos adelantado.

También los niños visibles en el fondo del sepulcro conservado de los Velasco son parecidos a los que, decapitados, sostienen los almohadones de los condes de Nieva: incluso el detalle de flexionar la pierna derecha de uno de los pajes guadalupanos es idéntico a lo que vemos en Valverde. La ubicación de los pajes (un paje y una doncella) tristes en la cabecera del sepulcro valverdeño alude al sufrimiento humano ante la muerte de la persona a la que se sirvió fielmente en vida. Afirma Azcárate que "es una constante en los sepulcros del decenio 1460-1470, en relación con el taller de Egas Cueman". Así, se ven pajes similares en el sepulcro de don Alfonso Téllez de Girón, en Belmonte (década de 1460), o en el de don Alvaro de Luna y su esposa en la catedral de Toledo, obra contratada por Sebastián de Almonacid. Otros ejemplos similares cita Azcárate en el mencionado trabajo ${ }^{63}$. Todo lo dicho justifica la atribución del hermoso sepulcro de Valverde al taller de Egas Cueman.

Como manifiesta don Elías Tormo en la introducción del citado artículo de Rubio y Acemel dedicado a las obras guadalupanas, "el estilo escultórico del maestro Egas es personal e inconfundible" ${ }^{94}$. Eso nos ha parecido cuando hemos

60 En el sepulcro definitivo el ángel se sustituyó por la Virgen mostrando un libro al Niño Jesús.

61 La cuidada caligrafía de las inscripciones sepulcrales citadas es sospechosamente parecida a la de la firma de Egas: las formas de la u, e y m son similares a las del epígrafe de los condes.

62 Sobre el sepulcro de los Velasco véanse, entre otros trabajos, Germán Rubio e Isidoro Acemel, "La escultura española en el siglo XV", 192-229; José Ramón Mélida Alinari, Catálogo Monumental de España. Provincia de Cáceres (Madrid: Ministerio de Instrucción Pública,1924),II,134-140.Véase, asimismo, Florencio-Javier García Mogollón, Imaginería Medieval extremeña, 101-102.

63 De Azcárate Ristori, "El maestro Sebastián de Toledo", 20.

64 Germán Rubio e Isidoro Acemel, "La escultura española en el siglo XV", p. 194 de la introducción. 
podido analizar detenidamente, con motivo de su restauración y limpieza, el sepulcro valverdeño, que creemos obra excelente salida del taller del notable maestro flamenco.

$$
* * *
$$

La obra valverdeña, de gran calidad, como hemos comprobado, se realizó en los últimos decenios del siglo XV, tiempo en el que se produjeron notables cambios en el arte español. Así, el estilo gótico medieval y su particular tendencia naturalista hispano-flamenca, que luce una gran riqueza decorativa, dio paso paulatinamente a los nuevos modos renacentistas italianos, con los que en un primer momento se mezcla. Gran relevancia en ese tránsito tuvo la ciudad de Toledo que, a mediados del siglo XV, era el centro principal de la escultura castellana y prevalecía sobre Burgos ${ }^{65}$. En la ciudad imperial trabajaron dos de los más afamados maestros del momento, los hermanos Hanequín (14421470/75) y Egas de Bruselas. El primero fue sobre todo arquitecto: el 13 de febrero de 1442 ya era maestro de obras de la sede toledana ${ }^{66}$ y hacia el año 1448 dirigía el último cuerpo de la torre catedralicia. No obstante, piensan los investigadores que han tratado el tema que ya debía de llevar varios años asentado en la urbe, quizá desde finales de la década de 1430. Es probable que le acompañara su hermano Egas, autor del sepulcro de Valverde, aunque éste no aparece documentado hasta 1454. Hanequín también supervisó la portada de los Leones de dicha catedral (1452-1465), en cuya obra colaboró Egas además de otros notables escultores: Juan Alemán, Francisco de las Cuevas, Juan Guas, etc. ${ }^{67}$. Debió de ser Hanequín el introductor del estilo flamígero de influencia

65 Véase el trabajo de José María de Azcárate Ristori, "Castilla en el tránsito al Renacimiento", en España en las crisis del arte europeo. Coloquios celebrados en conmemoración de los XXV años de la fundación del Consejo Superior de Investigaciones Cientificas (Madrid: CSIC, 1968), 129-136.

66 Amalia María Yuste Galán, "La introducción del arte flamígero en Castilla: Pedro Jalopa, maestro de los Luna", Archivo Español de Arte LXXVII, 307 (2004): 296-297,300. Véase, también, Francisco Pérez Sedano, "Notas del archivo de la Catedral de Toledo", en Datos Documentales Inéditos para la Historia del Arte Español I (Madrid: 1914), 16, y Manuel R. Zarco del Valle, "Documentos de la catedral de Toledo", en Datos Documentales para la Historia del Arte Español II (Madrid: 1916), 3 y 8-9. Una breve nota sobre los Egas recoge Ceán Bermúdez en sus adiciones a la obra de Eugenio Llaguno y Amirola, Noticias de los arquitectos y arquitectura de España desde su restauración (Madrid: 1829; Madrid: facsímil de Ediciones Turner, 1977), I, 133 y 253. Algunos datos más incorporan Dorothee Heim y Amalia María Yuste Galán, "La torre de la catedral de Toledo y la dinastía de los Cueman. De Bruselas a Castilla", Boletín del Seminario de Estudios de Arte y Arqueología de la Universidad de Valladolid LXIV (1998), 229-253. También puede consultarse el trabajo de Rafael Domínguez Casas, "El entorno familiar y social del escultor Egas Cueman de Bruselas", Archivo Español de Arte LXVIII (1995): 341-352.

67 Véase, al respecto, José María de Azcárate Ristori, Arquitectura gótica toledana del siglo XV (Ma-drid: 1958); ídem, "El maestro Hanequín de Bruselas", Archivo Español de Arte (1948):173188;ídem, “Análisis estilístico de las formas arquitectónicas de la Puerta de los Leones de la catedral de Toledo", en Homenaje al Profesor Cayetano de Mergelina (Murcia: Universidad, 1961-62), 97-122; Agustín Durán Sanpere y Juan Ainaud de Lasarte, Escultura gótica, vol. VIII de "Ars Hispaniae" (Madrid: 
flamenca en Toledo ${ }^{68}$ y se le atribuye la preciosa capilla de Don Álvaro de Luna dispuesta en la girola de la catedral ${ }^{69}$. Falleció Hanequín entre los años 1470$1475^{70}$.

Pero ahora nos interesa más su hermano Egas de Bruselas, llamado comúnmente Egas Cueman o Coeman, Koeman en lengua flamenca; como dice Lorne Campbell ${ }^{71}$, probablemente se relacionó con una familia de canteros que vivió en Bruselas en el siglo XV, el más notable de los cuales fue Henrik Coeman, documentado desde 1419 y autor de la colegiata de San Pedro y San Guido en Anderlecht y de la colegiata de Santa Gúdula de Bruselas. Como ya hemos adelantado, Egas labró obras fundamentales de la escultura gótica hispano-flamenca. Recordemos que colaboró con Juan Guas en la espectacular decoración de San Juan de los Reyes (Toledo) desde $1479^{72}$, palacio de los duques del Infantado (Guadalajara) y luego, a comienzos de la década de 1490, participó también con Juan Guas y con Martín Bonifacio en el trascoro de la sede toledana; como ya hemos dicho, en Guadalupe realizó el sepulcro de los Velasco (14671476) y el monumento funerario del obispo de Córdoba don Gonzalo de Illescas (1458), que antes había sido prior del monasterio. También realizó para el convento extremeño tres grupos escultóricos de madera policromada que debieron de pertenecer a un Vía Crucis y que hoy permanecen en el Museo, tras la restauración de Francisco Arquillo y después de haber permanecido demasiado tiempo padeciendo las inclemencias meteorológicas en el claustro: La Crucifixión, El Descendimiento y El Santo Entierro. Hace años analizamos exhaustivamente estas obras ${ }^{73}$ y ya apuntábamos con toda claridad, como Durán Sanpere y Ainaud de Lasarte, a la autoría de Egas, maestro sin duda muy influido por la obra pictórica de Rogier van der Weyden: se observa una gran relación entre el rostro de la Virgen guadalupana y el de la Virgen del parteluz de la toledana

Plus Ultra, 1956), 308 y ss.; Leopoldo Torres Balbás, Arquitectura gótica, vol VII de "Ars Hispaniae" (Madrid: Plus Ultra, 1952), 266;G. C. von Konradsheim, "Hanequin Coeman de Bruxelles. Introducteur de l'Art Flamand du XVe s. dans la región toledane",Mélanges de la Casa de Velázquez XII (1976):128131; Joaquín Yarza Luaces, La Edad Media, vol II de la "Historia del Arte Hispánico" (Madrid: Edit. Alhambra, 1978), 397 y 406.

68 Torres Balbás, Arquitectura gótica, 266.

69 Yarza Luaces, La Edad Media, 397 y 406.

70 Hemos tomado estos datos, en lo fundamental, de nuestro citado trabajo Imaginería medieval extremeña, 104.

71 Lorne Campbell y José Juan Pérez Preciado, Rogier van der Weyden y los reinos de la Península Ibérica, 40.

72 José María de Azcárate Ristori,"Sentido y significación de la arquitectura hispano-flamenca en la corte de Isabel la Católica: datos documentales", Boletín del Seminario de Estudios de Arte y Arqueología de la Universidad de Valladolid 37 (1971): 222.

73 Florencio-Javier García Mogollón, Imaginería medieval extremeña, 103-105. 
puerta de los Leones; también la Virgen con el Niño del tímpano ${ }^{74}$ interior (1458-1465) de dicha portada de los Leones tiene mucho que ver con la que corona el sepulcro de los Velasco ${ }^{75}$ obra, como sabemos, de Cueman. Don Elías Tormo y Monzó dató las referidas estaciones de Vía Crucis entre los años 1469 y $1472^{76}$, tiempo en el que fue prior del monasterio fray Juan de Guadalupe ${ }^{77}$.

Es probable que la Virgen del Coro del monasterio de Guadalupe también sea obra de Cueman, como ya afirmamos hace años relacionándola con la mencionada Virgen del sepulcro de los Velasco, también obra suya ${ }^{78}$. Por cierto, en ningún trabajo hemos atribuido la citada Virgen del Coro de Guadalupe al maestro Guillermín de Gante, como afirma Fuentes Ortiz ${ }^{79}$, cuyo artista se documenta en la catedral de Toledo en $1500^{80}$, a comienzos del mismo año informó sobre la sillería de Guadalupe realizada por el entallador Gonzalo Montenegro y actuó en la segunda década del siglo XVI en iglesias de la Vera ${ }^{81}$. También realizó Egas para Guadalupe, por encargo del obispo de Zamora Juan de Meneses, el sepulcro de su padre don Fernando Álvarez de Meneses (h. 1478), que se perdió con motivo de las reformas llevadas a cabo en el templo durante el siglo XVIII. Quizá se debe a su taller el pequeño relieve marmóreo de la Anunciación de la Virgen que permanece junto a la reja de la capilla de Santa Ana en la basílica guadalupana $^{82}$.

Son, por tanto, varias y muy importantes las obras que Egas Cueman dejó en Extremadura, especialmente en Guadalupe. Por ello no es de extrañar que debido a la fama del artista y a la conexión guadalupana del conde de Nieva a través de fray Juan de Illescas, su confesor y albacea testamentario, se

74 En dicho tímpano Egas colaboró posiblemente con los escultores Juan Alemán y Francisco de las Cuevas. Sobre la intervención de Cueman en Guadalupe y en la Puerta de los Leones de la catedral de Toledo véase también Harold E. Wethey, "Anequín de Egas Cueman, a Fleming in Spain”, The Art Bulletin 19, no 3 (sep. , 1937): 381-401.

75 Florencio-Javier García Mogollón, Imaginería medieval extremeña, 102.

76 Elías Tormo y Monzó, El monasterio de Guadalupe y los cuadros de Zurbarán (Madrid: 1906), 18, nota 1. Véase, asimismo, Agustín Durán Sanpere y Juan Ainaud de Lasarte, Escultura gótica, 314.

77 Rufino Blanco Sánchez "Para la historia del monasterio de Guadalupe. Noticias de un códice interesante", Revista de Archivos, Bibliotecas y Museos XXII (1910): 475.

78 Florencio-Javier García Mogollón, Imaginería medieval extremeña, 101-102 y 107-108. Sobre la Virgen del Coro guadalupana véase también Arturo Álvarez Álvarez, “¿Quién fue el autor de la Purísima del coro de Guadalupe?”, Guadalupe 827 (2012): 14-19.

79 Fuentes Ortiz, "La capilla de Gonzalo de Illescas en el Monasterio de Guadalupe: un proyecto de Egas Cueman", 120, nota 70.

25 .

80 Pérez Sedano, Datos documentales inéditos para la historia del arte español (Madrid, 1914), I,

81 Florencio-Javier García Mogollón, Viaje artístico por los pueblos de la Vera, 199 y 237; Florencio-Javier García Mogollón, “Cultura y evangelización: aproximación”, 140. Sobre la Virgen del Coro guadalupana, vid., Florencio-Javier García Mogollón, Imaginería medieval extremeña, 107-108.

82 Florencio-Javier García Mogollón, Imaginería medieval extremeña, 109-110. 
encargaran a Cueman la arquitectura y bultos del sepulcro valverdeño, considerando también la cercanía a las tierras toledanas. En cuyo sepulcro trabajó casi coetáneamente a sus obras guadalupanas.

Intervino también Cueman en la sillería coral de la catedral de Cuenca, conservada en la colegiata de Belmonte, obra que contrató, junto a su hermano Hanequín, antes del 6 de marzo de 1454, fecha en la que se comprometieron a iniciarla siendo obispo Lope de Barrientos(1445-1469) ${ }^{83}$ : el prelado, en su testamento del 17 de noviembre de 1454, recordó el contrato otorgado para realizar la sillería con el "maestro Haniquin, vezino de Toledo" 84 . En julio 1457 se hizo un pago a los citados maestros por el trabajo realizado, pero luego la sillería fue ampliada por diversos artífices, como el llamado maestro Lorenzo (1479), entre otros $^{85}$. Lorne Campbell opina que la actual sillería de Belmonte es obra nueva que reemplazó a la original de los $C_{\text {Cueman }}^{86}$. No obstante, creemos que algo de los Cueman queda en la actual sillería conquense, sin duda ampliada desde el último cuarto del siglo XV sobre el núcleo original de los maestros flamencos ${ }^{87}$. También intervino Cueman como colaborador de Juan Guas, desde 1480, en los deliciosos detalles decorativos del palacio de los Duques del Infantado (Guadalajara).

Egas Cueman, que se autocalificaba humildemente como "pedrero" y que cremos autor del magnífico sepulcro de Valverde de la Vera, falleció en 1495 siendo aparejador vitalicio de la fábrica catedralicia toledana, puesto en el que le sucedió su hijo Antón Egas, hermano del notable arquitecto Enrique Egas ${ }^{88}$.

83 Ya dijimos que Barrientos fue posiblemente el puente que unió a Guadalupe con Cueman, a través del obispo jerónimo Gonzalo de Illescas, confesores ambos de Juan II.

84 Lorne Campbell y José Juan Pérez Preciado, Rogier van der Weyden y los reinos de la Península Ibérica, 41.

85 María González Sánchez-Gabriel, "Los hermanos Egas de Bruselas en Cuenca. La sillería de coro de la Colegiata de Belmonte", Boletín del Seminario de Estudios de Arte y Arqueología de la Universidad de Valladolid IV (1936-39): 21-34; Gema Palomo Fernández, "Nuevos datos documentales sobre la sillería de coro gótica de la Catedral de Cuenca: de Egas de Bruselas a Lorenzo Martínez”, Archivo Español de Arte LXVII, 267 (1994): 284-291.

86 Lorne Campbell y José Juan Pérez Preciado, Rogier van der Weyden y los reinos de la Península Ibérica, 41.

87 Azcárate Ristori piensa que a Egas, como escultor, "se debe asignar por entero la construcción de esta sillería, hoy en la colegiata de Belmonte de Cuenca". Véase de Azcárate Ristori, "El maestro Hanequín de Bruselas", 182.

88 José María de Azcárate Ristori, “Antón Egas”, Boletín del Seminario de Estudios de Arte y Arqueología de la Universidad de Valladolid XXIII (1957): 5-7. 


\section{APÉNDICE DOCUMENTAL}

"Posesión que tomó el señor Diego López de Çúñiga por carta del Rey don Juan de la villa de Valverde". 15 y 22 de julio de 1455. Archivo Histórico de la Nobleza. ALTAMIRA. C.3,D.227.

"En la villa de Valuerde de la Vera de Plasençia a XXII días del mes de jullio año del nascimiento de nuestro Saluador Ihesuxristo de myll e quatroçientos y çinquenta y çinco años, este dicho día estando el concejo e omes buenos de la dicha villa ayuntados a canpana repiada segund que lo a de uso y de costunbre delante de las puertas de la yglesia de Santa María de la dicha villa y estando presentes en el dicho ayuntamiento y conçejo Juan Sánchez Tirado, alcalde, e Antonio Sánchez Tirado, regidor del dicho concejo, e otros muchos omes buenos de la dicha villa y su tierra e en presencia de mi el escriuano y testigos yuso escriptos pareció y presente el magnífico señor Diego López de Çúñiga e dixo por sy y en nonbre de doña Leonor Nyno su muger, hija del señor yllustrísimo don Pedro Nyno, defunto que Dios aya, que por quanto ella y él en su nombre tenyendo e poseyendo la dicha villa de Valuerde e la villa de Talauán con sus fortalezas con toda su tierra, pacíficamente y con el señorío y jurisdicción e mero misto imperio dellas, García de Herrera por sy y en nonbre de doña María Nyno su mujer, fija de el dicho señor, quel diz que forçadamente vino dentrar y tomar la posesyón de la dicha villa de Valuerde e fortaleza della, para lo qual el rey nuestro señor avia mandado secrestar la dicha villa de Valuerde e su fortaleza y que agora su alteza mandaua quitar y alçar la dicha secrestaçión e que mandaua quel dicho Diego López de Çúñiga e la dicha doña Leonor su muger tobyesen la dicha posesión dela según paresçía por una carta del dicho señor rey escrita en papel e firmada de su nonbre e registrada en sus espaldas, de la qual el dicho señor Diego López dixo que hazía e hyzo presentación en este dicho conçejo, su tenor de la qual es este que se sygue:

Yo el rey ynvío a saludar a vos los conçejos de las villas de Valverde e Talavera (sic), ya sabéys como por la toma que García de Herrera hyzo desas villas e fortalezas yo las mandé secrestar en Gómez de Benavides e agora por quanto entre las partes de Garzía de Herrera e Diego Destúñyga es mandado que los devates que en uno han sean vistos e determynados por los condes de Plasençia e de Alba. Por ende my merced e boluntad es de alçar e quytar e por la presente alço e quyto la dicha secrestaçión e mando que la posesyón de las dichas villas e fortaleza tenga el dicho Dyego de Çúñyga e doña Leonor su muger según que la tenyan antes quel dicho García de Herrera las entrase e tomase. Fecha en la çibdad de Córdoba a quinze días del mes de julio año del nascimyento de nuestro salvador Ihesuxristo de myll e quatroçientos e çinquenta e 
çinco años. Yo el Rey, yo el dottor Fernando Díaz de Toledo hoydor e refrendador del rey e su secretario la fyze escribyr por su mandado, en las espaldas de la dicha carta estaba este que se sigue registrada alba más ( $\mathrm{sic}$ ), e la dicha carta de dicho señor rey leyéndola en este dicho concejo por my el dicho escriuano luego el dicho señor Diego López dixo que por sy y en nonbre de la dicha su mujer quería e entendía contynuar su posesyón de la dicha villa de Balberde, con el señorío e juridiçión de ella e con la dicha fortaleza, recobrando otrosy qualquyer posesyón que en qualqyer manera quel e la dicha su muger obyesen pedido porque lo entendia continuado e tomado e tomaba e recobraba protestando su derecho e de la dicha su muger queda a salvo contra los dichos Garzía de Herrera e doña María Nyno su muger a quales quyas penas e otras cosas a que haya derecho alguno contra ellos, e que por tomar esta posesyón dixo que no entendía renunçya ni renunciaba su derecho más que todo le quedase entero. E luego el dicho señor Diego López dixo que contynuando e recobrando la dicha posesyón e que en señal de contynuaçión e recobramyento della que tomaba e tomó al dicho Juan Sánchez Tyrado, alcalde susodicho, una bara que tenya en la mano e dixo que de hallí lo pribaba e pribó de dicho ofycio de alcaldía e ansymesmo pribaba e pribó a Pedro Sánchez alcalde con él e que es ygual grado e al dicho Alfón Sánchez Tyrado e a Bartolomé Sánchez, regidores de dicho conçejo e alguazil de la dicha villa, los quales dichos Pedro Sánchez, alcalde, e Bartolomé Sánchez, regidor, no paresçieron y presentes, e dixo que los mandaba e mandó que no husasen más de los dichos ofyçios los quales dixo que adquería e tomaba en sy y en señal de contynuaçión de la dicha su posesyón e dixo que nonbraba e ponya e nonbró e puso por alcalde de la dicha villa de Balverde al dicho Juan Sáchez Tyrado que lo antes hera e por regidor del dicho conçejo della al dicho Alfonso Tyrado los quales estaban presentes, e fue luego dellos resçibydo juramento en la señal de la cruz en las palabras de los santos ebangelios en que cada uno dellos puso su mano según forma de derecho que byen ellos e verdaderamente usarán de los dichos ofyçios, conbyene a saver el dicho Juan Sánchez de la dicha alcaldía el dicho Alfonso Sánchez de dicho regimyento. Guardándose luego el mandado de los dichos señores Diego Lopes e doña Leonor su muger e que dobyeren su probecho que serán en se lo allegar e dobyeren su daño e desde luego en que se lo arredrarán en quanto pudieren e que donde ellos no pudieren que se lo harán saver lo más ayna que pudieren... (Diego López otorga todo su poder cumplido a los alcaldes etc.)

Dixo que entendía recobrada e tomada la dicha posesyón de la dicha villa de Valverde e fortaleza della e juridiçión mero misto ynperio della e de su fortaleza e que para corroboraçión dello que mandaba e mandó a los sobredichos conçejo, alcalde e regidor e omes buenos que presentes estaban que por 
reconoçimiento de lo que dicho es le besasen la mano e luego los sobredichos que presentes estaban de la dicha villa de Valverde le besaron la mano derecha... (se citan los testigos)

E después desto en la dicha villa este dicho día del dicho mes e año luego yncontynente en presençia de my el dicho escrivano e de los testigos de yuso escritos el dicho señor Diego López fue a la casa e fortaleza de la dicha villa e abrió las puertas dela y entróse dentro en ella e andaba de pyes corporalmente por ella contynuando e recobrando la posesyón y en señal de ello çerró las puertas de la dicha casa e después abriolas e dixo que se haçía por entero della por sy y en el dicho nonbre e desto e de cómo pasó el dicho señor Diego López pydyó a my el dicho escrivano que se lo diese ansy por testymonyo synado con my sino, testigos...." El resto del documento tiene poco interés, porque reitera los nombramientos de alcalde, regidor, oficiales etc.

\section{REFERENCIAS BIBLIOGRÁFICAS}

Agapito y Revilla, Juan. "Casamiento de doña Juana de Navarra, hija natural de don Carlos III el Noble, con Íñigo Ortiz, hijo de Diego López de Estúñiga, justicia mayor del Rey de Castilla". Boletín de la Real Academia de la Historia LXXXI (noviembre de 1922): 383-414 y, especialmente, 386-87.

Álvarez Álvarez, Arturo. “¿Quién fue el autor de la Purísima del coro de Guadalupe?”. Guadalupe 827 (2012): 14-19.

Azcárate Ristori, José María de. "El maestro Hanequín de Bruselas". Archivo Español de Arte (1948):173-188.

-. "Antón Egas". Boletín del Seminario de Estudios de Arte y Arqueología de la Universidad de Valladolid XXIII (1957): 5-7.

Azcárate Ristori, José María de. Arquitectura gótica toledana del siglo XV. Madrid: 1958.

- "Análisis estilístico de las formas arquitectónicas de la Puerta de los Leones de la catedral de Toledo". En Homenaje al Profesor Cayetano de Mergelina, 97-122 . Murcia: Universidad, 1961-62.

—. "Castilla en el tránsito al Renacimiento". En España en las crisis del arte europeo. Coloquios celebrados en conmemoración del los XXV años de la fundación del Consejo Superior de Investigaciones Científicas, 129-136. Madrid: CSIC, 1968, 129-136.

—. "Sentido y significación de la arquitectura hispano-flamenca en la corte de Isabel la Católica". Boletín del Seminario de Estudios de Arte y Arqueología de la Universidad de Valladolid XXXVII (1971): 222-223. 
—. "El maestro Sebastián de Toledo y el Doncel de Sigüenza". Wad-al-Hayara: revista de estudios de Guadalajara 1 (1974): 26.

Beltrán Llavador, Rafael. Un estudio sobre la biografía medieval castellana: la realidad histórica de Pero Niño y la creación literaria de "El Victorial”. Valencia: Universidad, 1987.

Beltrán Llavador, Rafael (edición, estudio y notas). Gutierre Díez de Games, El Victorial. Madrid: RAE, 2014.

Blanco Sánchez, Rufino. "Para la historia del monasterio de Guadalupe. Noticias de un códice interesante", Revista de Archivos, Bibliotecas y Museos XXII (1910): 475.

Bueno Rocha, José. Notas históricas de Valverde de la Vera. Valverde de la Vera: Ayuntamieno, 1995.

Campbell, Lorne, y Pérez Preciado, José Juan. Rogier van der Weyden y los reinos de la Península Ibérica. Madrid: Museo del Prado, 2015.

Cátedra García, Pedro Manuel. La "Historia de la Casa de Zúñiga" otrora atribuida a Mosén Diego de Valera. Salamanca: Seminario de Estudios Medievales y Renacentistas, 2003.

Correa Pérez, Ángel. Historia del señorio de Valverde de la Vera. Asociación Cultural de Amigos de la Vera-Consejería de Cultura y Patrimonio de la Junta de Extremadura: 1998.

Diago Hernando, Máximo. "Linajes Navarros en la vida política de la Rioja. El ejemplo de los Stúñiga”. Príncipe de Viana 53, no 197 (1992): 575.

Díez de Games, Gutierre, El Victorial: Crónica de don Pedro Niño, conde de Buelna (h. 1436), manuscrito de la Biblioteca Nacional de España, MSS/17648.

Domínguez Casas, Rafael. "El entorno familiar y social del escultor Egas Cueman de Bruselas”. Archivo Español de Arte LXVIII, 272 (1995): 341-352.

Durán Sanpere, Agustín, y Ainaud de Lasarte, Juan. Escultura gótica, vol. VIII de "Ars Hispaniae”. Madrid: Plus Ultra, 1956.

Franco Silva, Alfonso. "Los dominios de los Velasco en tierras de La Rioja. El condado de Nieva (siglos XV-XVI)", en Os reinos ibéricos na Idade Media, Livro Homenagen al Professor Doutor Humberto Carlos Baquero. Oporto: 2002, 103-113.

Fuentes Ortiz, Ángel. "La capilla de Gonzalo de Illescas en el Monasterio de Guadalupe: un proyecto de Egas Cueman recuperado". Archivo Español de Arte XC, 358 (2017): 107-124.

García Mogollón, Florencio-Javier. Imaginería medieval extremeña. Esculturas de la Virgen María en la provincia de Cáceres. Cáceres: UEx-Edit. Extremadura, 1987.

—.Viaje artístico por los pueblos de la Vera (Cáceres). Catálogo Monumental. Madrid: Pedro Cid, 1988.

—. "La platería de la Diócesis de Plasencia". En VIII Centenario de la Diócesis de Plasencia (1189-1989). Jornadas de Estudios Históricos, 166. Plasencia: Caja de Ahorros, 1990. 
-. (director). Inventario artístico de Cáceres y su provincia. Tomo I. Partidos judiciales de Alcántara y Cáceres y comarca de la Vera de Cáceres. Madrid: Ministerio de Cultura, Instituto de Conservación y Restauración de Bienes Culturales, 1990.

- . "Cultura y evangelización. Aproximación a la iconografía de la Pasión de Cristo en el arte extremeño". Cauriensia, X (2015): 136 y 141.

González Sánchez-Gabriel, María. "Los hermanos Egas de Bruselas en Cuenca. La sillería de coro de la Colegiata de Belmonte". Boletín del Seminario de Estudios de Arte y Arqueología de la Universidad de Valladolid IV (1936-39): 21-34.

Heim, Dorothee, y Yuste Galán, Amalia María. "La torre de la catedral de Toledo y la dinastía de los Cueman. De Bruselas a Castilla". Boletín del Seminario de Estudios de Arte y Arqueología de la Universidad de Valladolid LXIV (1998): 229-253.

Konradsheim, G. C. von. "Hanequin Coeman de Bruxelles. Introducteur de l'Art Flamand du XVe s. dans la región toledane". Mélanges de la Casa de Velázquez XII, (1976): 128-131.

López de Haro, Alonso. Nobiliario Genealógico de los Reyes y Títulos de España. Madrid:1622, I, cap. XXII, 565.

Llaguno y Amirola, Eugenio. Crónica de don Pedro Niño, conde de Buelna, por Gutierre Díez de Games, su alférez. Madrid: Imprenta de Antonio de Sancha, 1782. Llaguno y Amirola, Eugenio, con las adiciones de Juan Agustín Ceán Bermúdez. Noticias de los arquitectos y arquitectura de España desde su restauración. Madrid: 1829; Madrid: facsímil de Ediciones Turner, 1977.

Mayero Higuero, Susana. Estudio histórico-artístico de Valverde de la Vera. Valverde de la Vera: 2007.

Mélida Alinari, José Ramón. Catálogo Monumental de España. Provincia de Cáceres. Madrid: Ministerio de Instrucción Pública, 1924.

Moreno Ollero, Antonio, Los dominios señoriales de la Casa de Velasco en la Baja Edad Media (Sanlúcar de Barrameda: 2014).

Novoa Pérez, José Manuel. Vasallos, señores y concejos en la Vera de Plasencia. Historia del señorio de Valverde de la Vera (siglos XIII-XVIII). Mérida: Academia Europea de Yuste, 2009.

Olivera Serrano, César. Beatriz de Portugal y la pugna dinástica Avis-Trastámara. Santiago de Compostela: CSIC, 2005.

Palomo Fernández, Gema. "Nuevos datos documentales sobre la sillería de coro gótica de la Catedral de Cuenca: de Egas de Bruselas a Lorenzo Martínez". Archivo Español de Arte LXVII, 267 (1994): 284-291.

Paredes Guillén, Vicente. Los Zúñiga, Señores de Plasencia. Cáceres: 1909.

Pérez Sedano, Francisco. "Notas del archivo de la Catedral de Toledo". En Datos Documentales Inéditos para la Historia del Arte Español I. Madrid: 1914.

Ramón y Fernández Oxea, José. "Iglesias cacereñas no catalogadas". Revista de Estudios Extremeños XVI, 1 (1960): 68. 
Rodríguez Puértolas, Julio. Poesía crítica y satírica del siglo XV. Madrid: Castalia, 1989.

Rubio, Germán, y Acemel, Isidoro (con introducción de Elías Tormo). "La escultura española en el siglo XV. El maestro Egas en Guadalupe”. Boletín de la Sociedad Española de Excursiones 20 (1912): 192-229.

Santos Canalejo, Elisa Carolina de. El siglo XV en Plasencia y su tierra. Cáceres: 1981. Tormo y Monzó, Elías. El monasterio de Guadalupe y los cuadros de Zurbarán. Madrid: 1906.

Torres Balbás, Leopoldo. Arquitectura gótica, vol VII de "Ars Hispaniae”. Madrid: Plus Ultra, 1952.

Valladares de Sotomayor, Antonio. Semanario erudito, que comprehende varias obras inéditas, críticas, morales, instructivas, políticas, históricas, satíricas y jocosas de nuestros mejores autores antiguos y modernos. Madrid: Blas Román, 1790, vol. XXIX, 51.

Velo Nieto, Gervasio. Castillos de Extremadura. Madrid: 1968.

Villacampa, Carlos G. Grandezas de Guadalupe. Estudios sobre la historia y las bellas artes del gran monasterio extremeño. Madrid: Imprenta de Cleto Vallinas, 1924.

Wethey, Harold E. “Anequín de Egas Cueman, a Fleming in Spain”. The Art Bulletin, 19, no 3 (sep., 1937): 381-401.

Yarza Luaces, Joaquín. La Edad Media, vol II de la "Historia del Arte Hispánico". Madrid: Edit. Alhambra, 1978.

Yuste Galán, Amalia María. "La introducción del arte flamígero en Castilla: Pedro Jalopa, maestro de los Luna”. Archivo Español de Arte LXXVII, 307(2004): 296297,300 .

Zarco del Valle, Manuel R. "Documentos de la catedral de Toledo". En Datos Documentales para la Historia del Arte Español II, 3 y 8-9. Madrid: 1916.

Florencio-Javier García Mogollón Departamento de Arte y Ciencias del Territorio Facultad de Filosofía y Letras

Universidad de Extremadura Av. Universidad, $\mathrm{s} / \mathrm{n}$. 10003 - Cáceres (España) https://orcid.org/0000-0001-8625-0438 


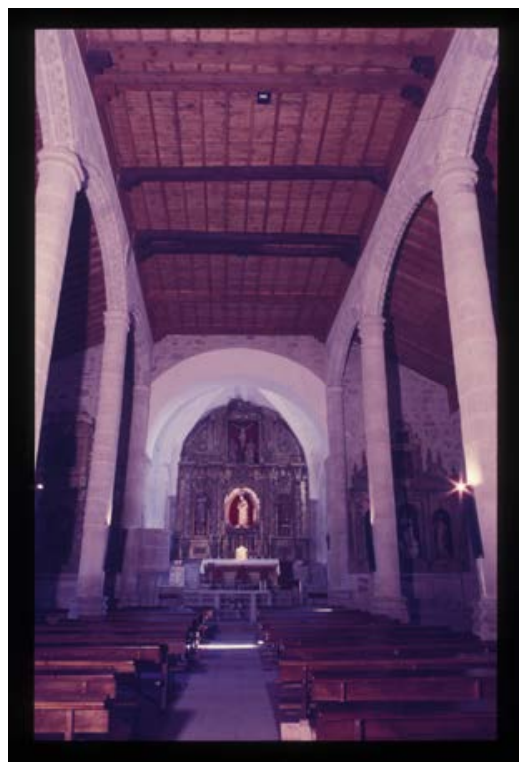

1. Templo parroquial. Interior hacia el ábside.

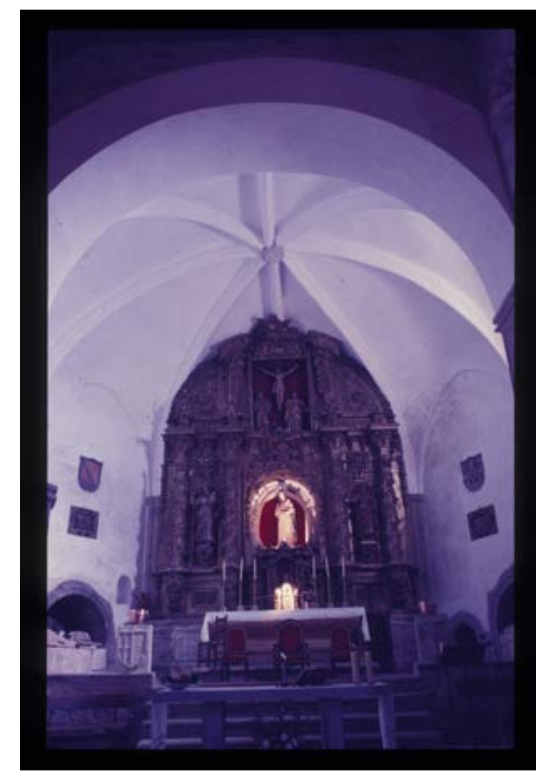

2. Ábside parroquial: Arcosolios en donde estuvieron los yacentes. 


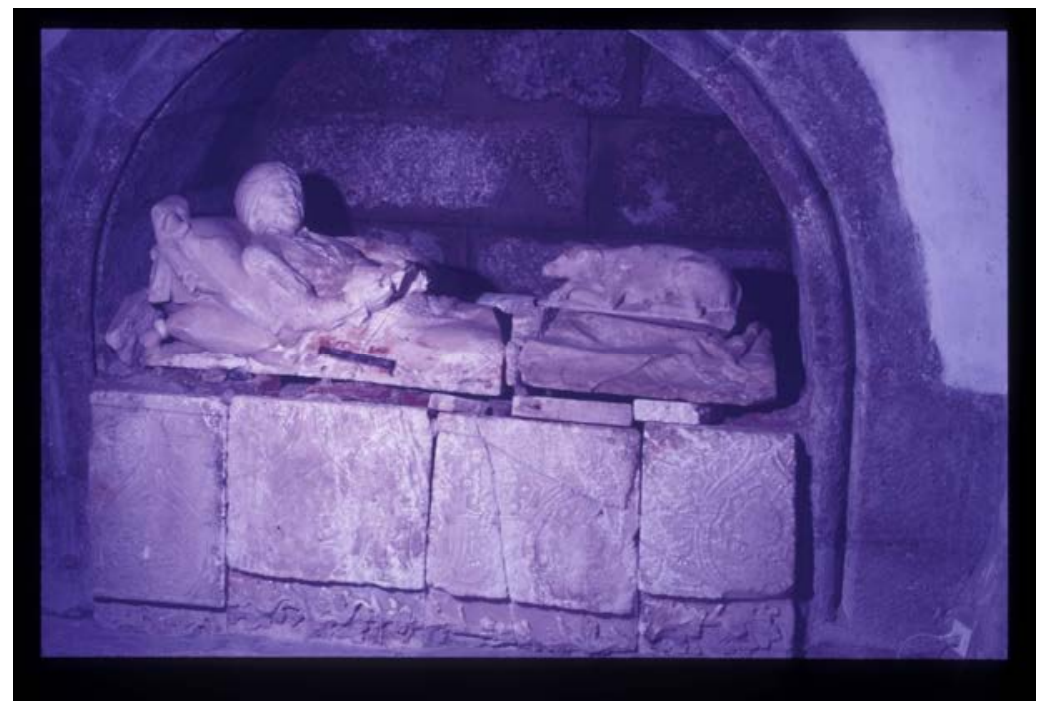

3. Sepulcro del conde de Nieva antes de la restauración.

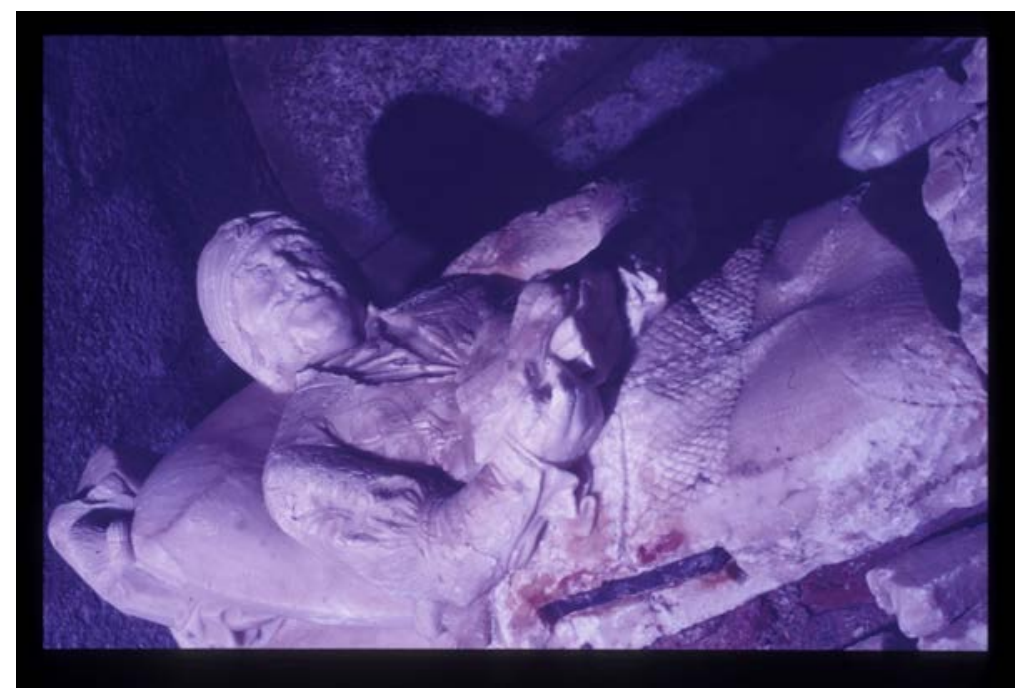

4. Detalle del conde de Nieva antes de la restauración. 


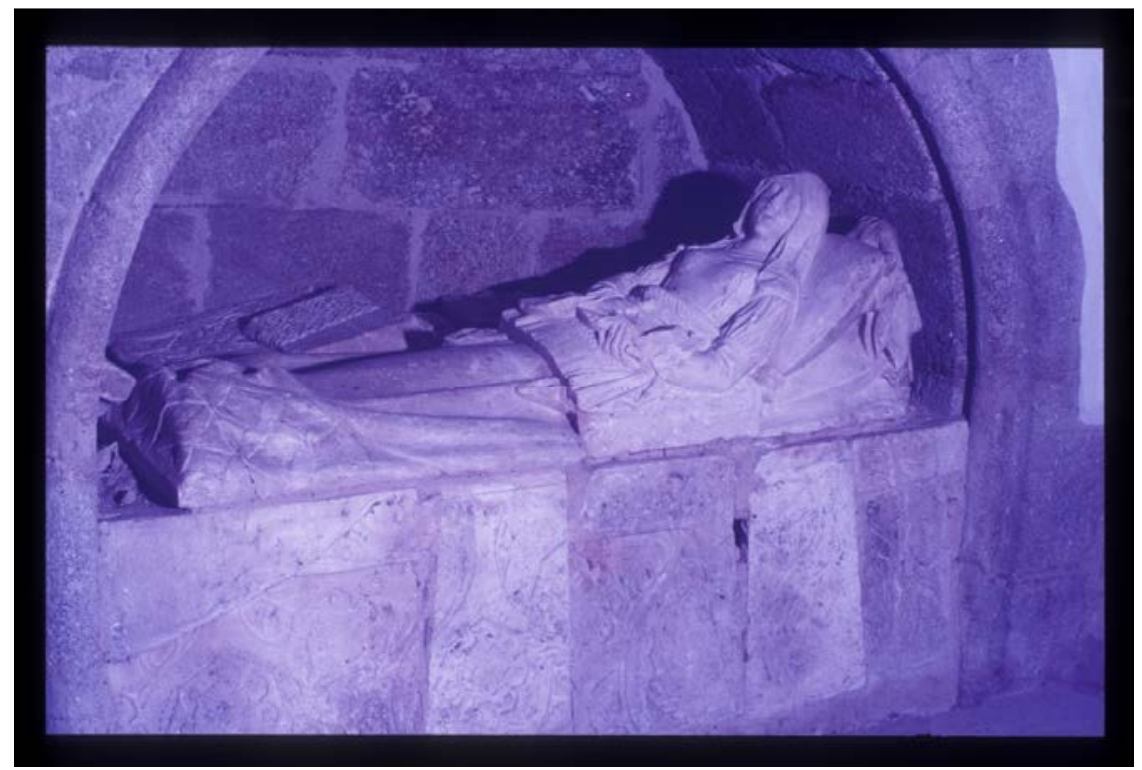

5. Condesa de Nieva antes de la restauración.

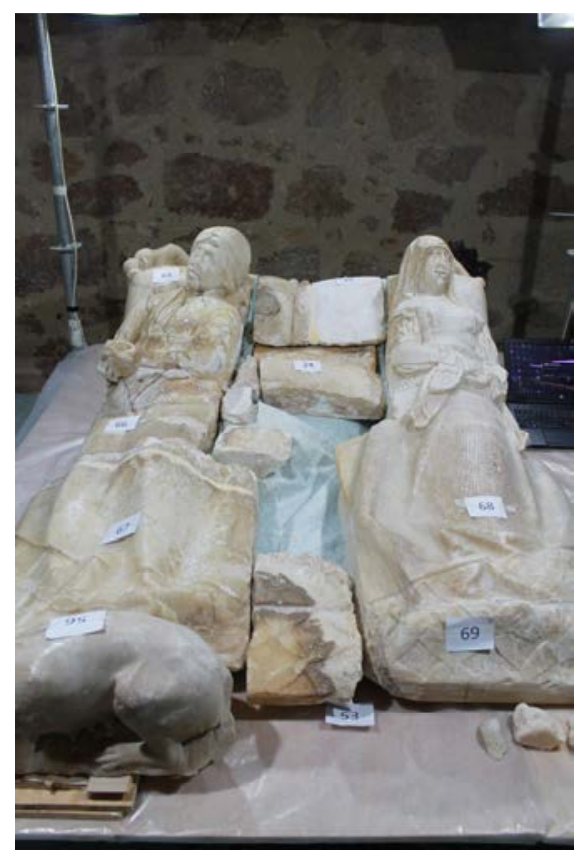

6. Vista general del sepulcro durante la restauración. 


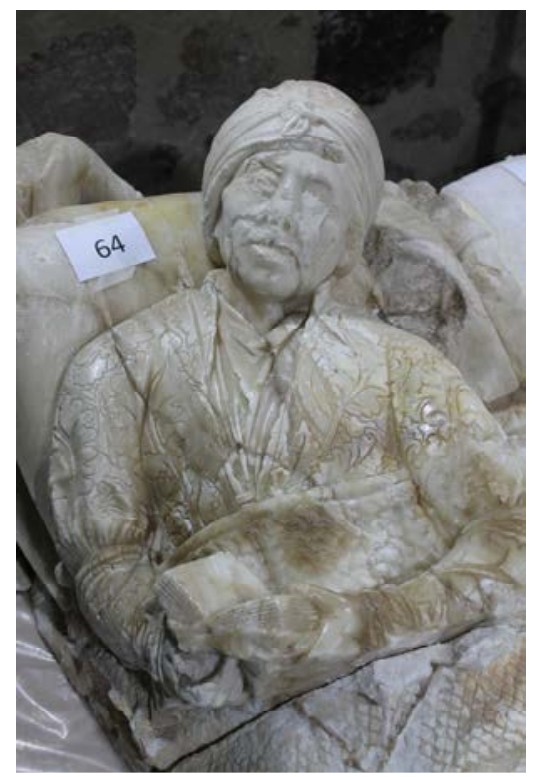

7. Conde de Nieva.

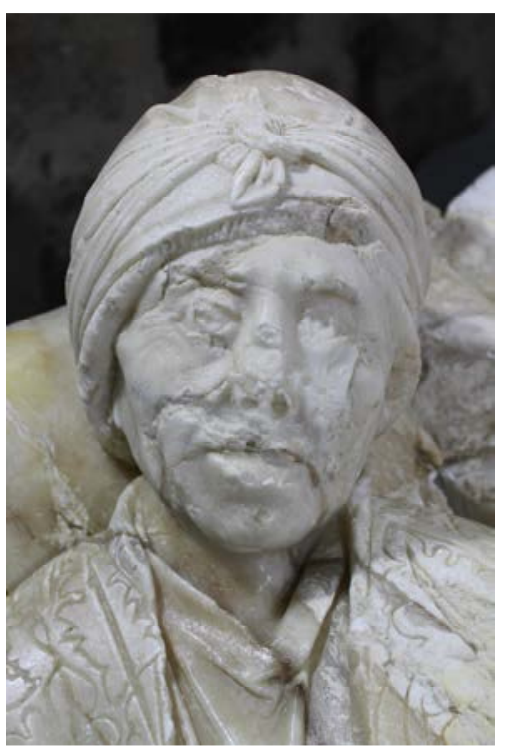

8. Detalle del Conde de Nieva. 


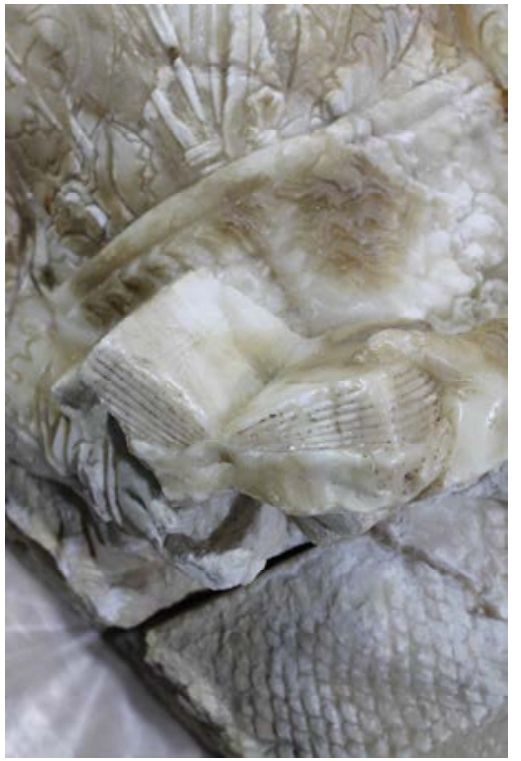

9. Detalle del Conde de Nieva.

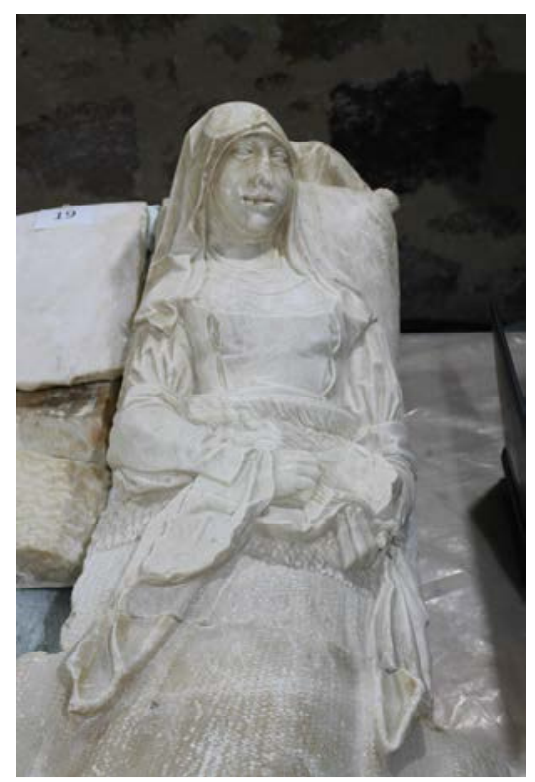

10. Condesa de Nieva. 


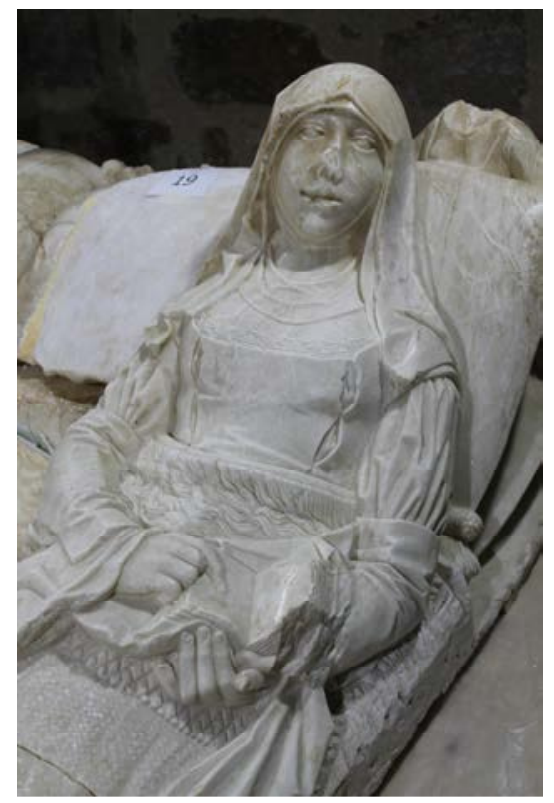

11. Detalle de la condesa de Nieva.

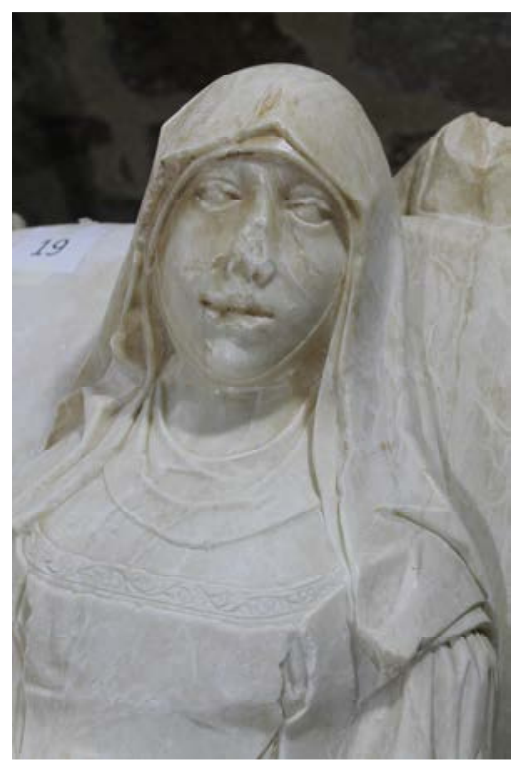

12. Detalle de la condesa de Nieva. 


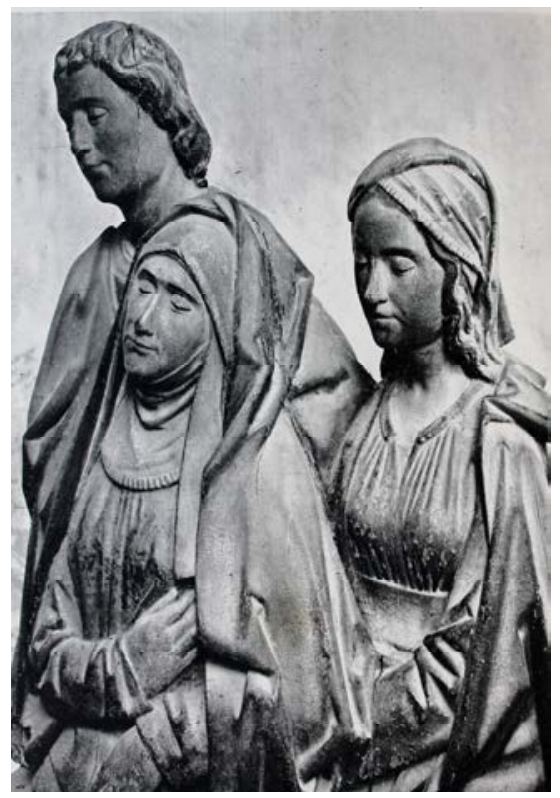

13. Monasterio de Guadalupe. Santo Entierro de Egas Cueman.

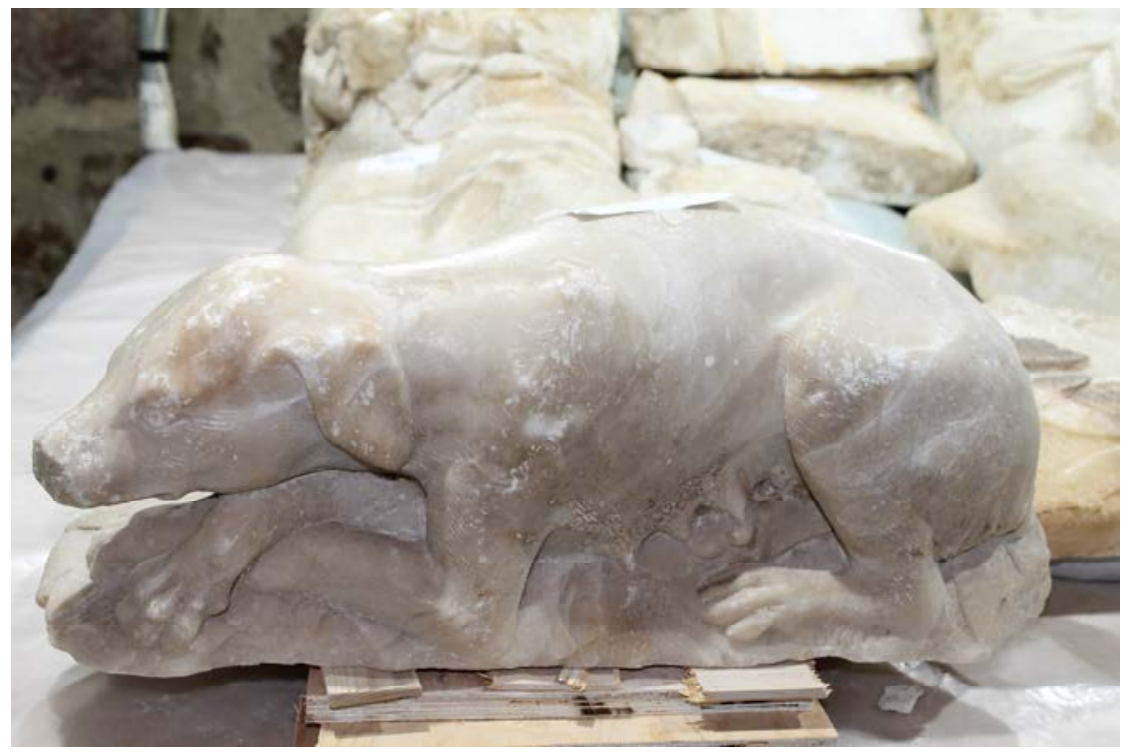

14. Perrita colocada a los pies de los condes. 


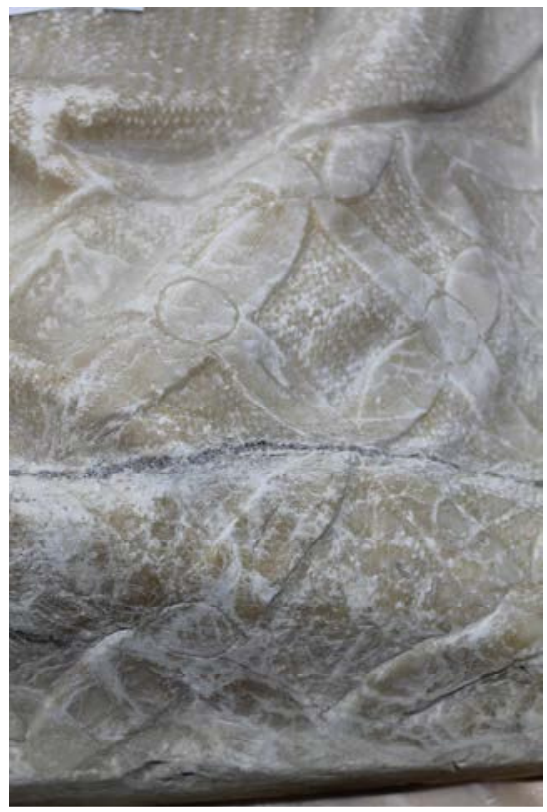

15. Detalle de la colcha que cubre a los difuntos.

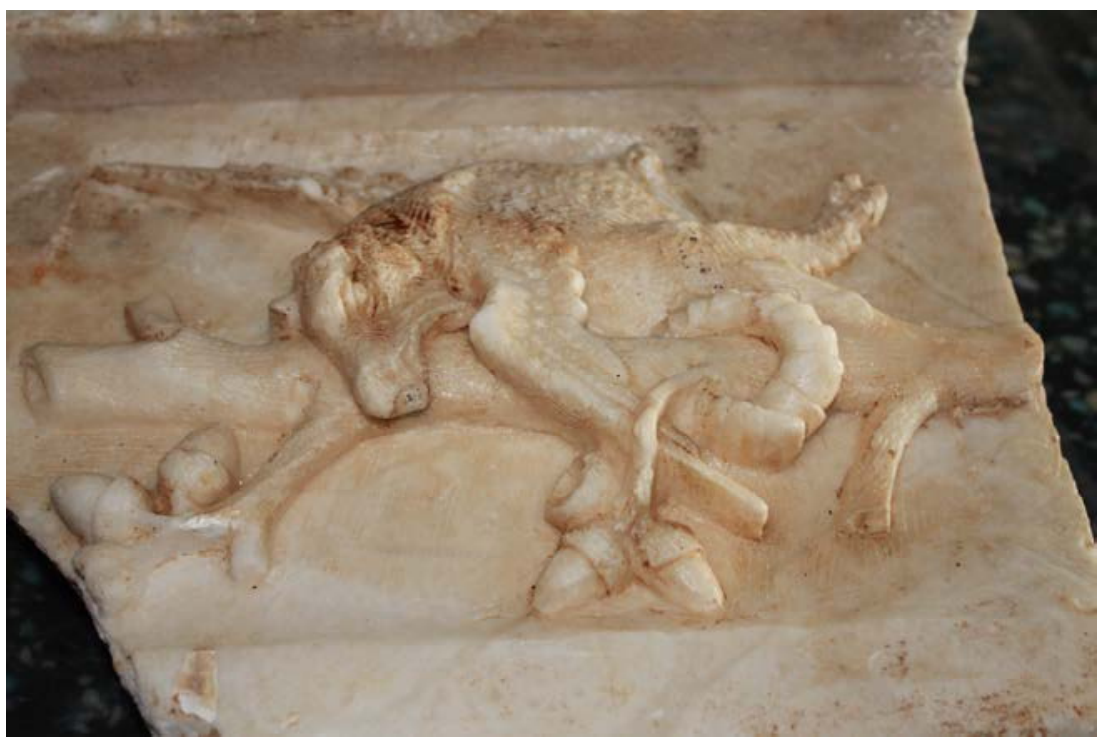

16. Placa decorativa: Dragón sobre rama de encina. 


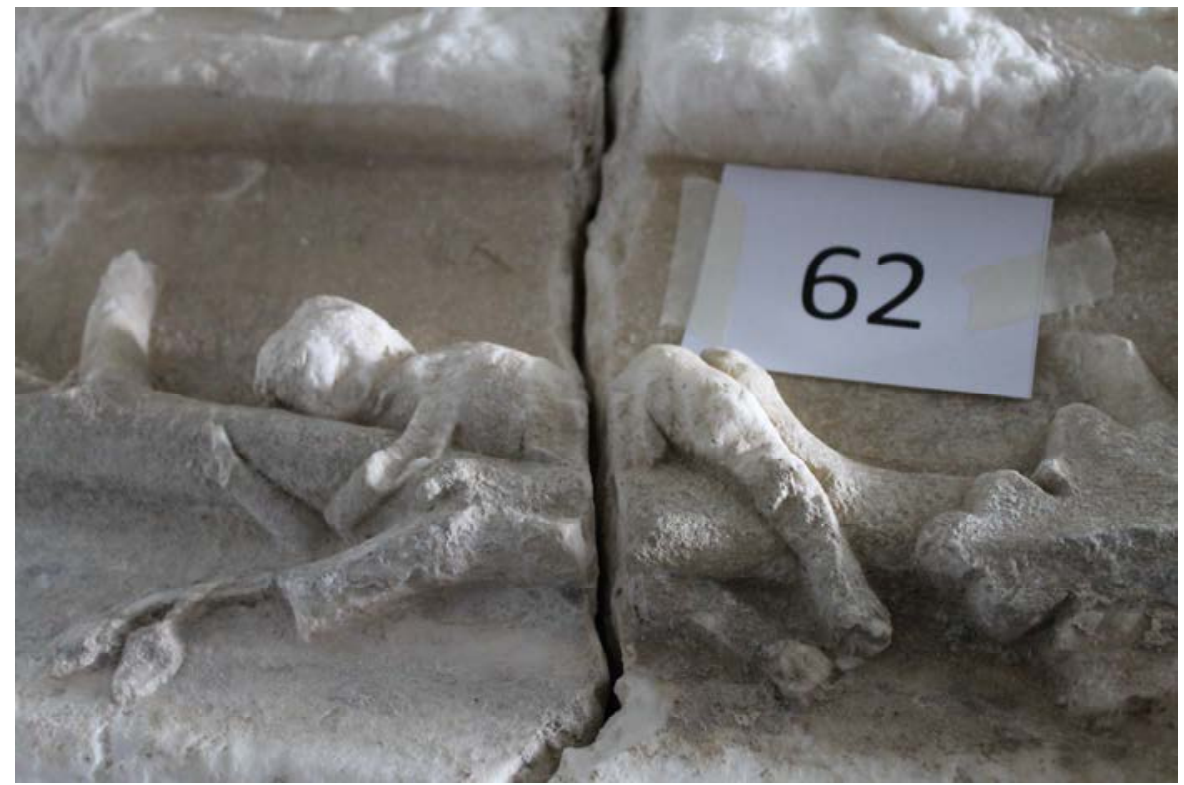

17. Placa decorativa: Hombre sobre rama.

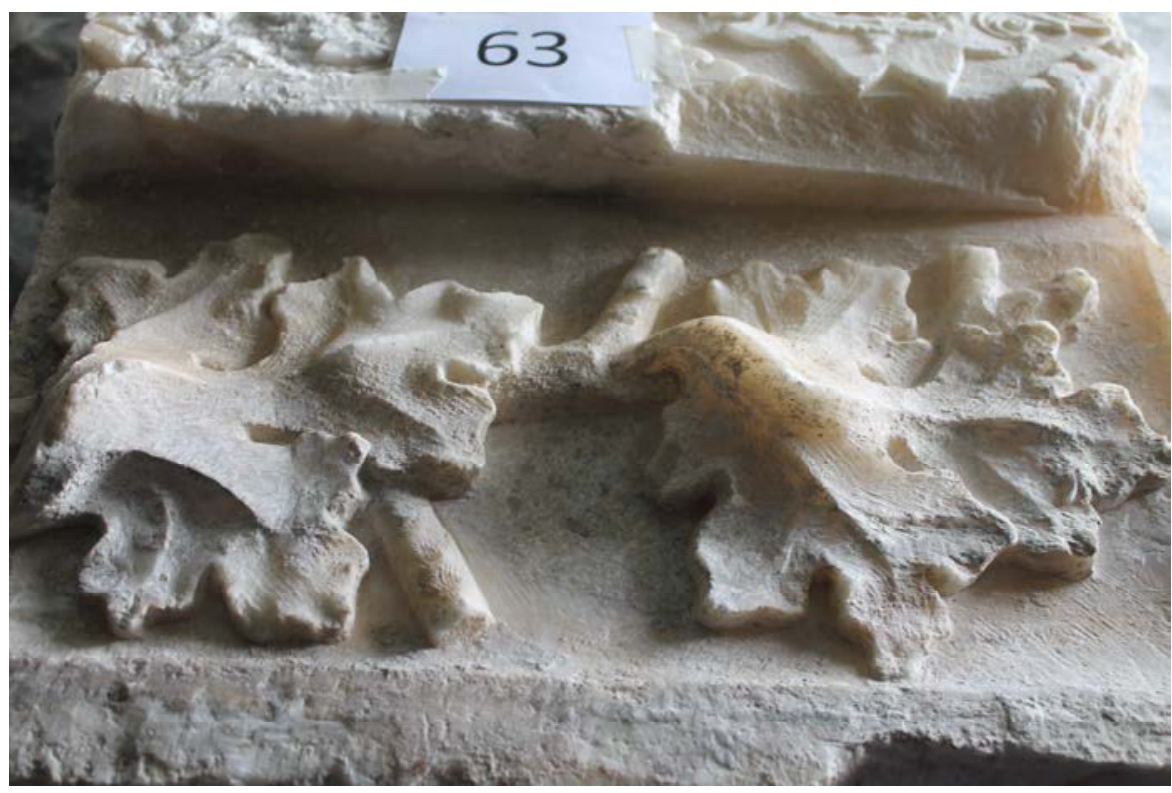

18. Placa decorativa: Cardinas. 


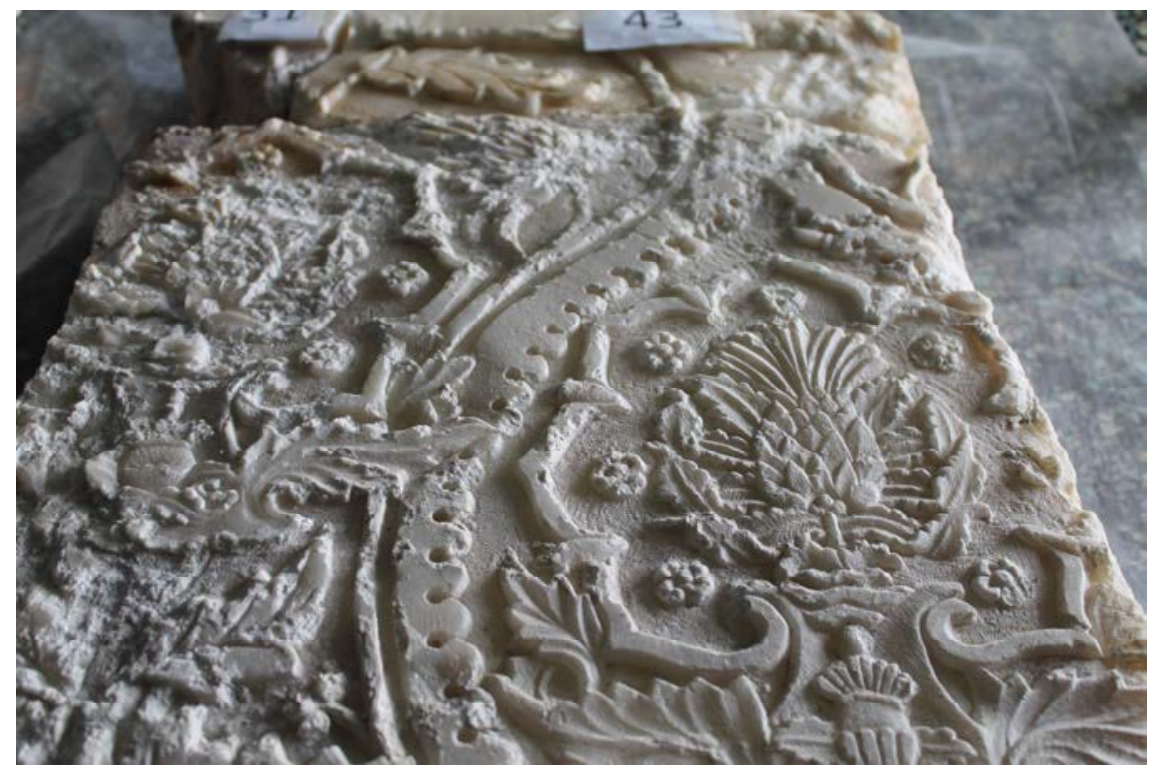

19. Placa decorativa: piñas y otros elementos vegetales.

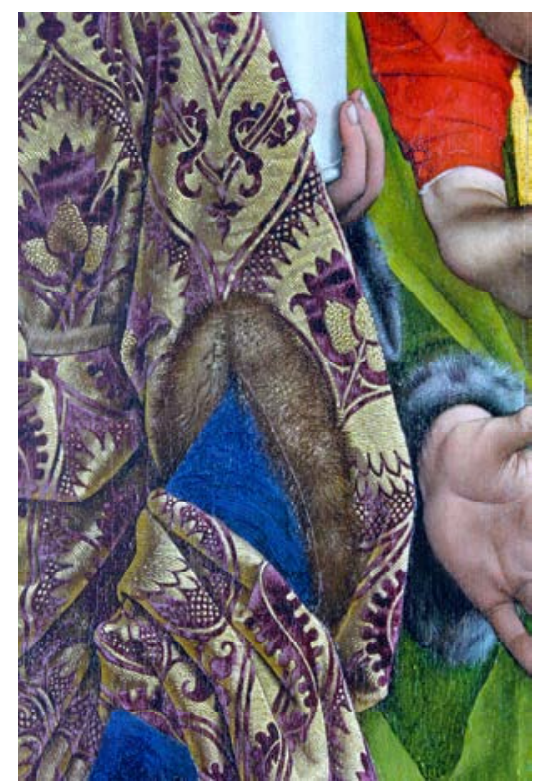

20. Rogier van der Weyden: Detalle del Descendimiento del Museo del Prado. 


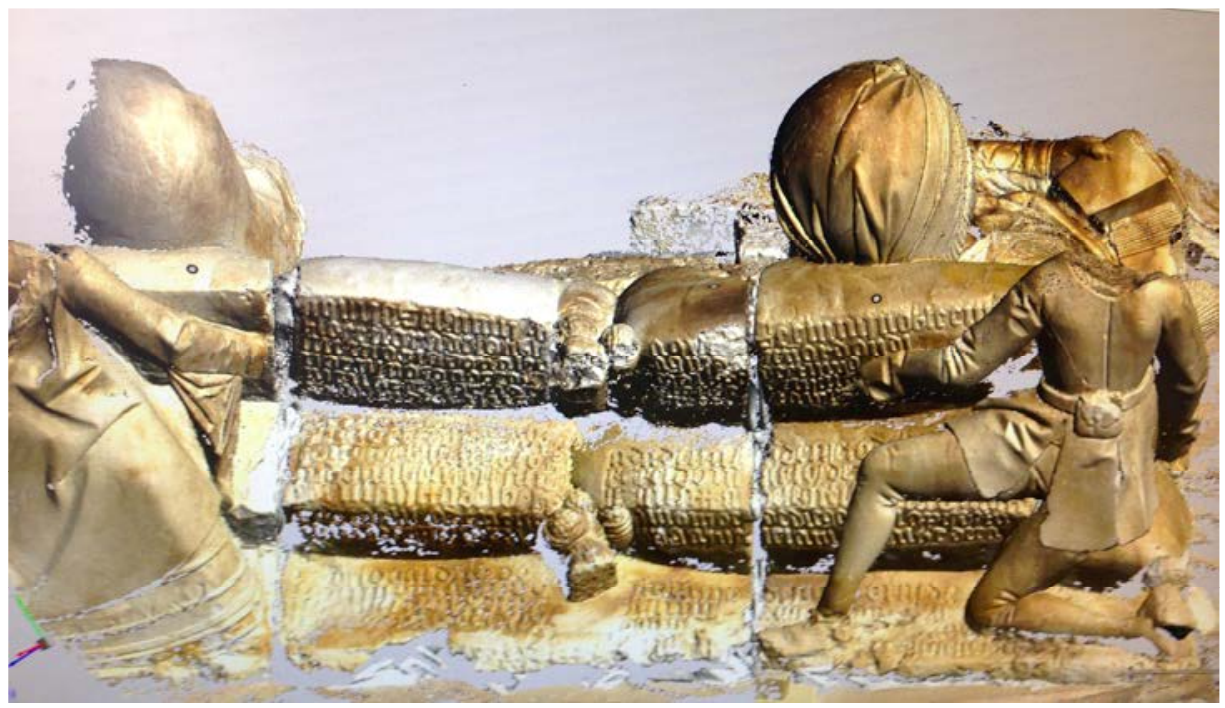

21. Almohadones con inscripción, paje y doncella sobre los que reposan los condes.

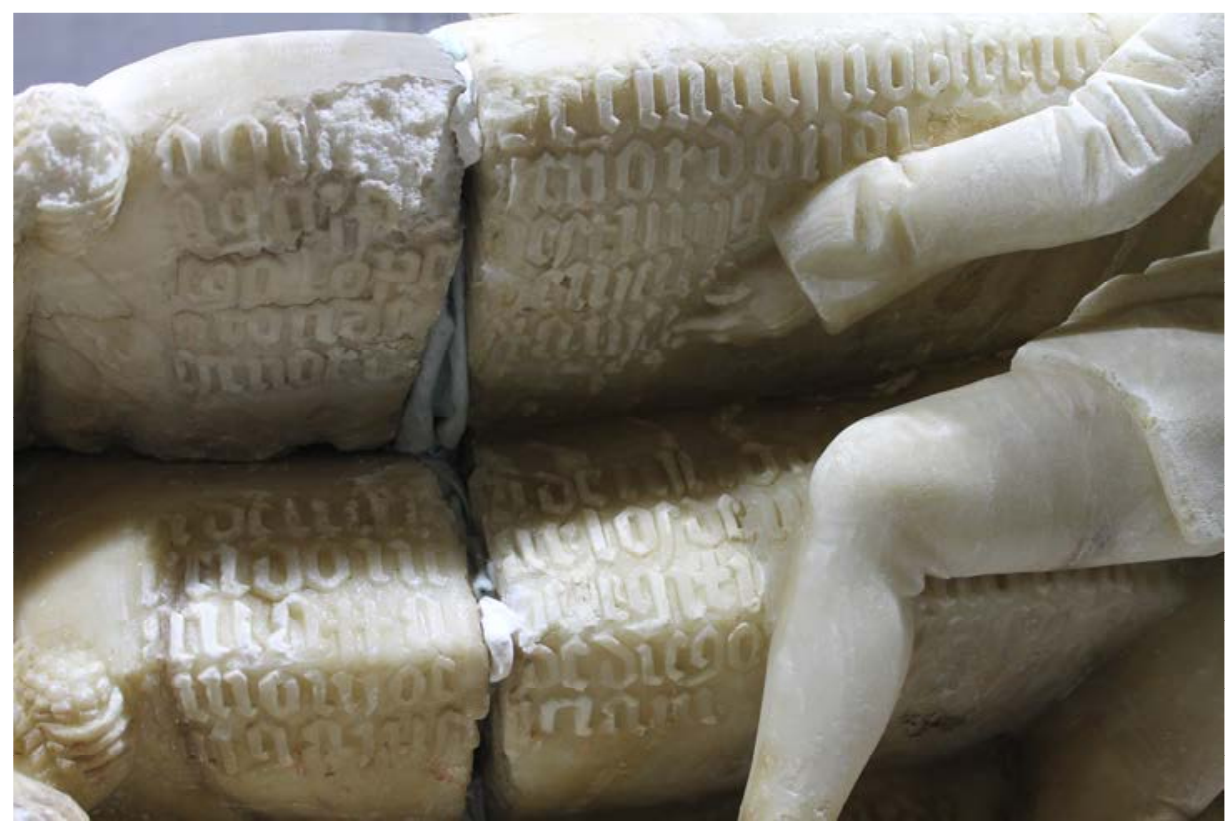

22. Epígrafe del conde. 


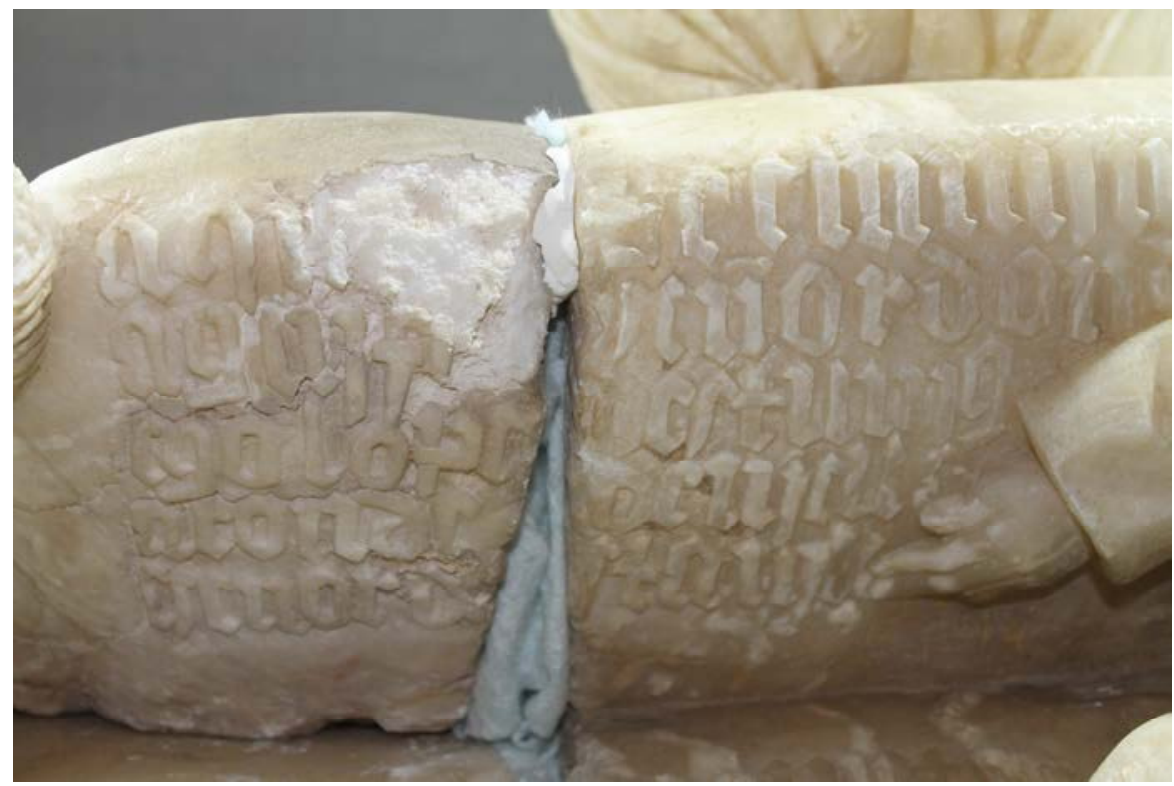

23. Detalle del epígrafe del conde.

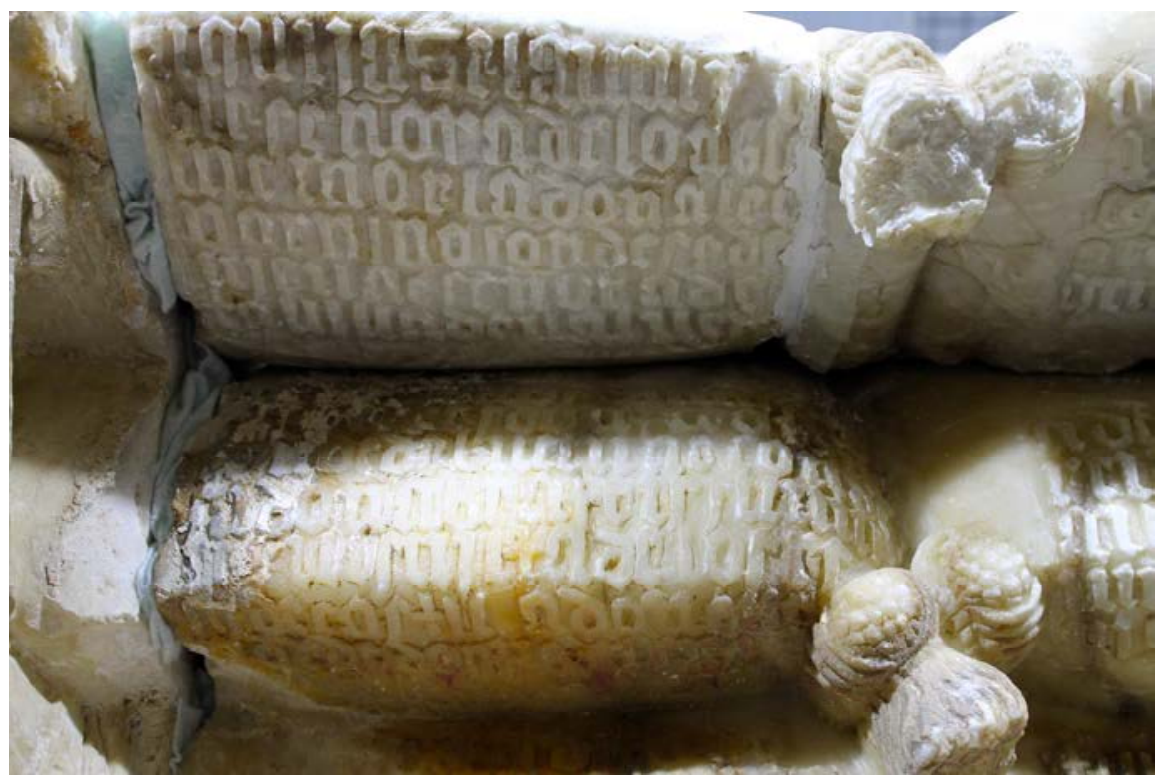

24. Epígrafe de la condesa. 


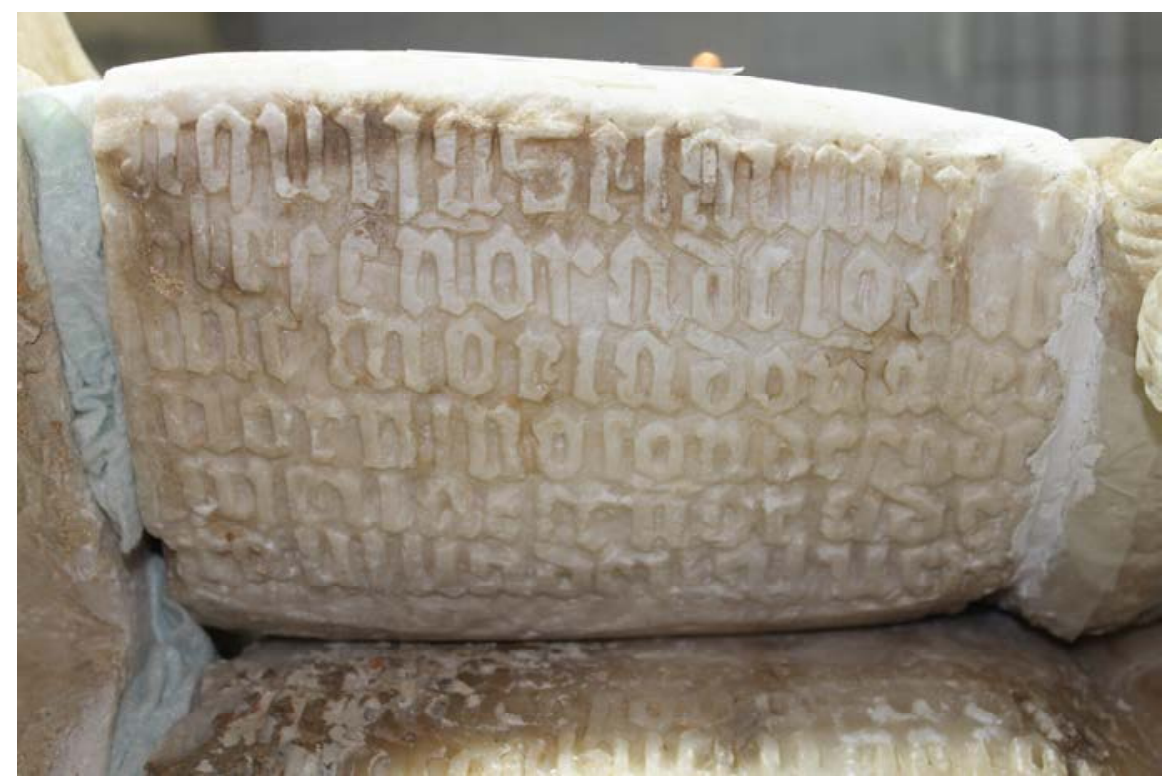

25. Detalle del epígrafe de la condesa.

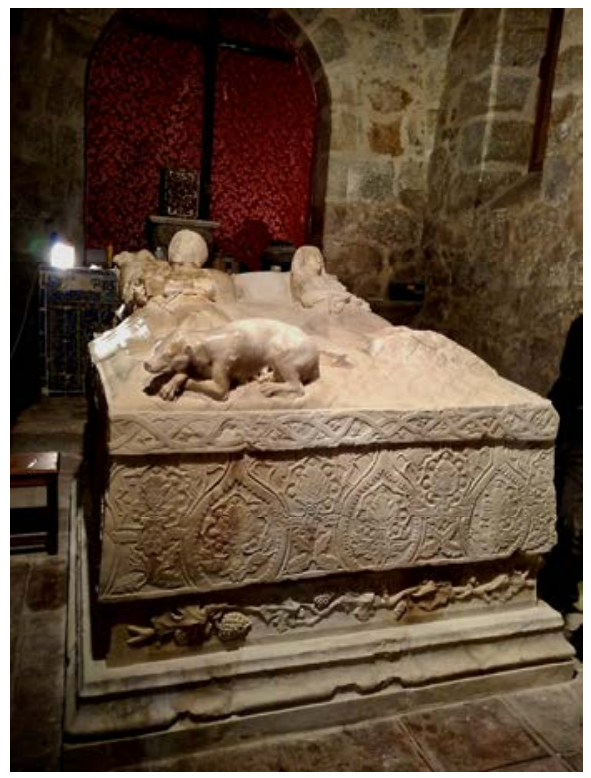

26. Vista del sepulcro restaurado e instalado desde los pies. 


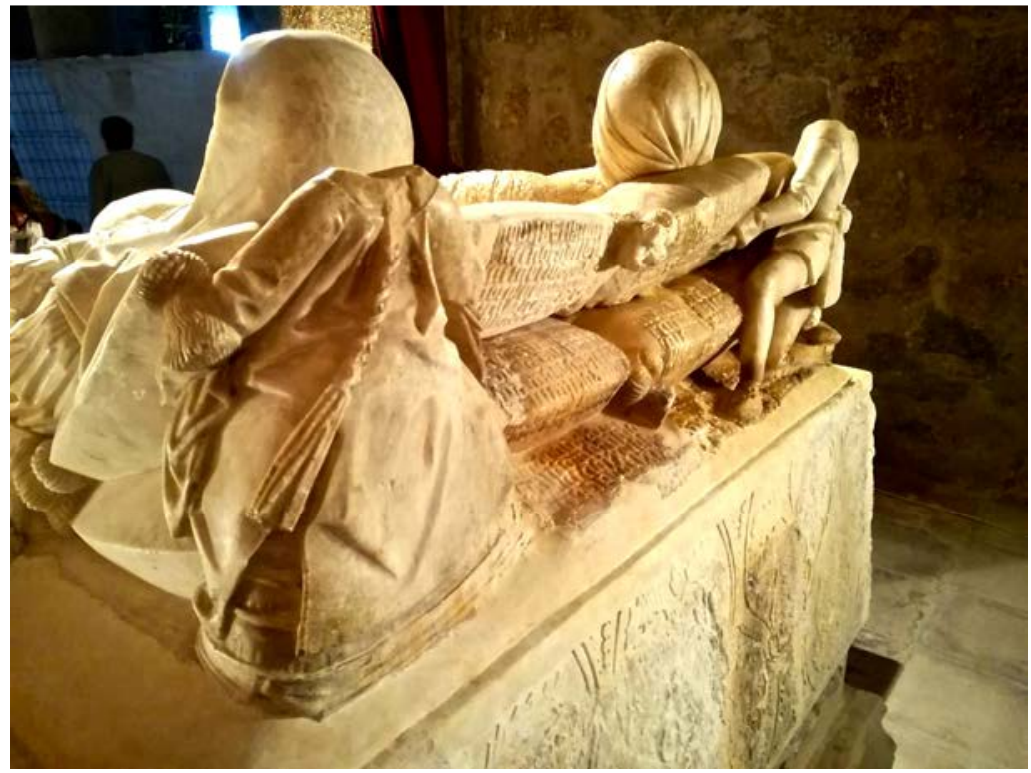

27. Cabecera del sepulcro restaurado.

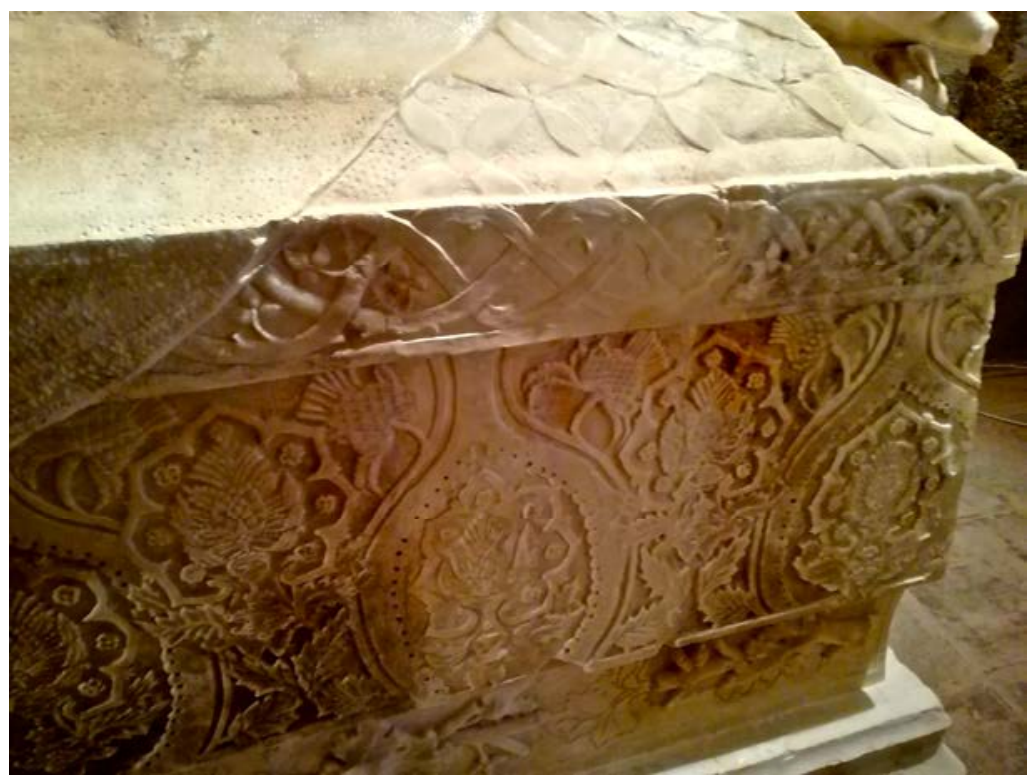

28. Detalle de la esquina de los pies del conde. 


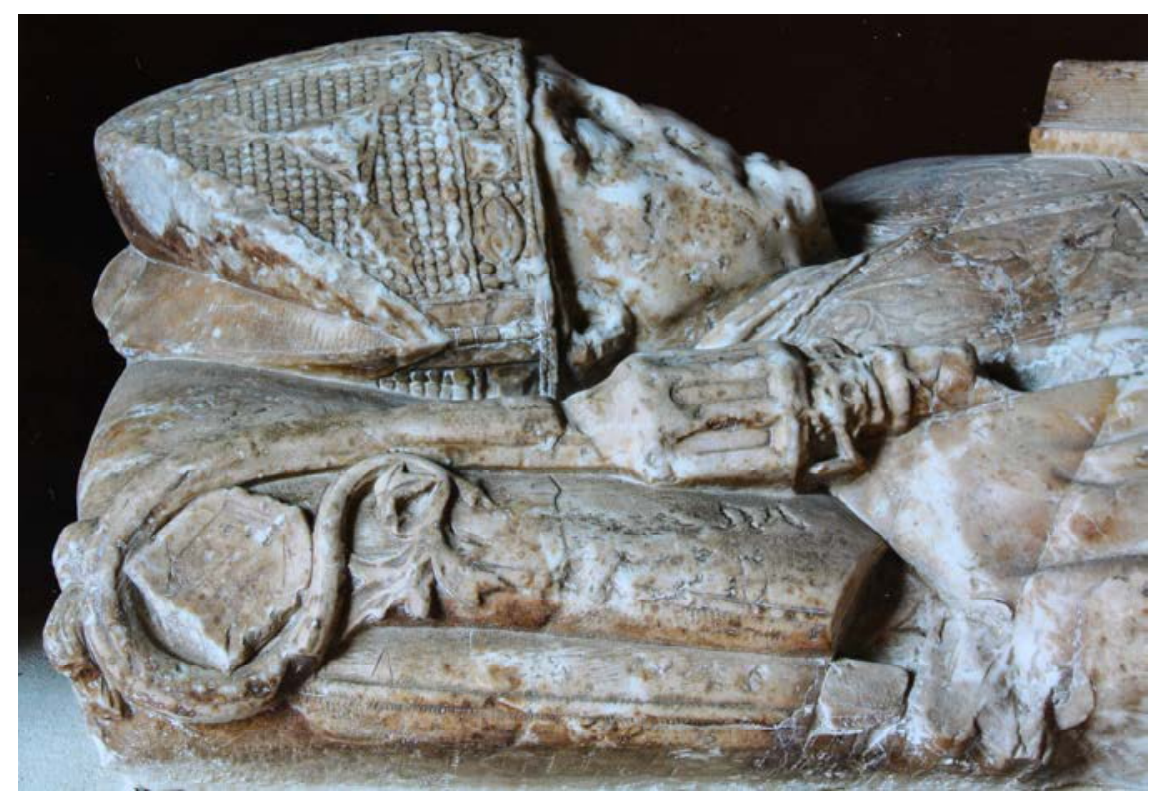

29. Monasterio de Guadalupe. Egas Cueman. Bulto funerario de Gonzalo de Illescas.

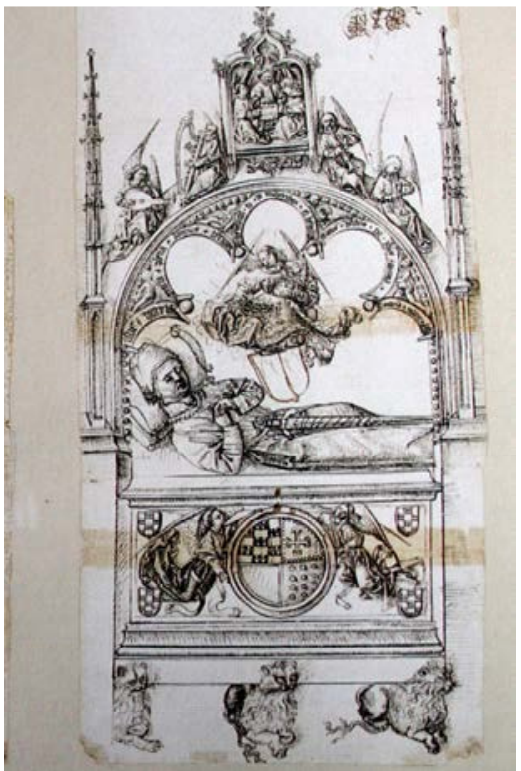

30. Monasterio de Guadalupe. Traza del sepulcro de los Velasco. Egas Cueman. 


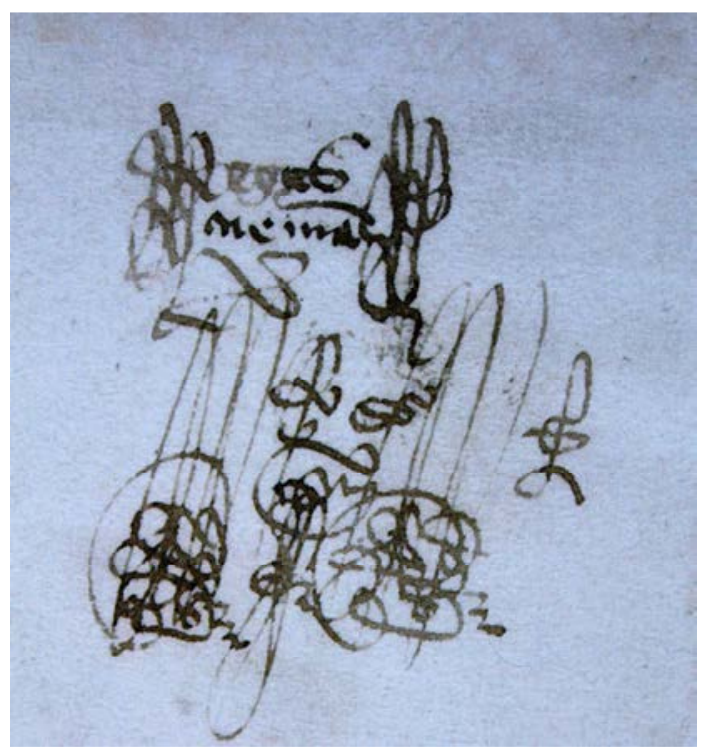

31. Monasterio de Guadalupe. Firma de Egas Cueman en la traza del sepulcro de los Velasco. 